\title{
Recovery of Mono-Ethylene Glycol Distillation and the Impact of Dissolved Salts Simulating Field Data
}

\author{
Sami Zaboon ${ }^{1}$, Adam Soames ${ }^{1}$, Varun Ghodkay ${ }^{1}$, Rolf Gubner ${ }^{1}$, Ahmed Barifcani ${ }^{1}$ \\ Chemical Engineering Department, Curtin University of Technology, Perth W.A, Australia
}

\begin{abstract}
This study was conducted to investigate the operation of a packed distillation column and analyse its performance during the separation of mono-ethylene glycol from water. The column was designed and constructed by the Curtin Corrosion Engineering Industry Centre (CCEIC) and operated in collaboration with a reputable oil company to generate experimental field data. A secondary investigation was then performed into the impacts of dissolved salts within the rich MEG feed upon the purity of the lean MEG product. It was observed through application of the FUG shortcut distillation design equations that six equilibrium stages were required to attain the experimental separations reported under continuous operation of the column. It was further determined that the packing utilised within the column had a Height Equivalent to a Theoretical Plate (HETP) of approximately 0.34 metres when no dissolved salts were present corresponding to an estimated packing height of approximately 1.7 metres. The impact of dissolved salts upon the performance of the column was evident through lower lean MEG purities observed during experimental operation of the column in comparison to salt free trials. The reduction in column performance was reaffirmed by Aspen HYSYS and Aspen Plus simulations of the field data, where salt trials resulted in lean MEG purities noticeably less than corresponding salt free experimental trials and simulated predictions. Overall, it was observed that the presence of dissolved salts during operation led to a reduction in MEG mass fraction of the final lean MEG product by on average $7.2 \%$. The impact of dissolved salts on lean MEG purity was successfully predicted by Aspen Plus simulation with an average accuracy of $1.61 \%$ through the inclusion of monovalent salt cations using the ELECNRTL equation of state with modified binary parameters. The reduction in lean MEG purity was attributed to boiling point elevation of the MEG-Water solution and the impact of the dissolved salts on the systems vapour liquid equilibrium.
\end{abstract}

Keywords: Mono-ethylene Glycol; MEG; Distillation; Salts; Simulation and Experimental Study; Field Data

\subsection{Introduction}

Mono-ethylene glycol (MEG) is an important raw material having numerous research and industrial applications, one such example is its application as a hydrate inhibitor in the hydrocarbon processing industry (Lu, Kan, and Tomson 2010). MEG is one of the most favoured thermodynamic hydrate inhibitors used in hydrocarbon transportation pipelines and processing facilities due to its low volatility, low toxicity, low flammability, favourable thermodynamic behaviour, simple and proven technology requirements and high availability (Bikkina et al. 2012, Haque 2012). Furthermore, the preference for using MEG over other traditional thermodynamic hydrate inhibitors such as methanol stems from several operational, environmental and safety issues imposed by the use of methanol and MEG's ability to be effectively recovered, regenerated and reused (AlHarooni et al. 2015, Haghighi et al. 2009). Due to the high cost of MEG and significant volumes required to provide effective hydrate control, following the hydrate inhibition process it is essential to separate MEG from the produced water so that it can be recycled and reused to minimize operating costs.

The most prevalent MEG recovery methods have been broadly categorised into two main process types, (i) reconcentration and (ii) regeneration (Bikkina et al. 2012). The reconcentration process is the most basic MEG recovery method and is comprised of a simple distillation column where the water rich MEG is concentrated to form lean MEG by vaporisation of the excess water. Typically, the distillation column is operated to regain a MEG purity within the range of $80-90 \%$ by weight as the bottoms product (Latta, Seiersten, and Bufton 2013, Carroll 2003). The reconcentration method for MEG recovery is applicable when no salts are expected to precipitate out during recovery, typically during the early production stages when the produced water contains just low amounts of dissolved salts (Bikkina et al. 2012, Brustad, Løken, and Waalmann 2005). As the reconcentration process only removes water from the MEG solution, any dissolved salts, pipeline corrosion products and additional non-volatile chemicals will accumulate inside the closed MEG loop. The accumulation of salt beyond saturation limits within 
the MEG system may result in severe fouling and plugging of equipment and flowlines, as such the salt must be either removed or the MEG periodically replaced (Son and Wallace 2000).

For cases where the rich MEG contains high quantities of dissolved salts, reclamation must instead be performed before the MEG can be reinjected at the well head to prevent damage to process equipment through excessive solid build-up. The reclamation of MEG can be performed using two different methods depending on the required final lean MEG salt concentration, by either full reclamation or slip-stream salt removal. The process of full reclamation entails a two-step process where the rich MEG solution is initially vaporized at low pressure (10-15 kPaa) leaving the salts and non-volatile solids remaining within a flash drum (Bikkina et al. 2012, Brustad, Løken, and Waalmann 2005). The salt free MEG solution is then reconcentrated by distillation to the required lean MEG specifications by the removal of water. Full reclamation is generally performed when high rates of formation water are expected over the lifetime of the processing facility.

Alternatively, slip stream regeneration may be performed when a certain level of dissolved salts can be tolerated within the closed MEG loop during processing. For low to medium formation water rates it is often more attractive to use the split-stream salt removal process to minimise operating costs and equipment size (Latta, Seiersten, and Bufton 2013). In performing split stream regeneration, the rich MEG solution first undergoes pre-treatment to remove light hydrocarbons, low soluble salts and corrosion products before conventional distillation is performed to remove excess water to achieve the desired MEG purity. Following distillation, the majority of the lean MEG undergoes salt removal via a reclaimer or ion exchange system to remove the remaining highly soluble salts. However, a fraction of the salty lean MEG stream by-passes the salt removal operation and mixes with the final salt free lean MEG. The slip-stream rate is typically determined by the allowable amount of soluble salts in the final lean MEG product required to prevent scaling in pipelines (Bikkina et al. 2012, Brustad, Løken, and Waalmann 2005).

The typical design and construction of MEG recovery columns utilise packed internals for columns of diameter $0.7 \mathrm{~m}$ and below due to the low pressure drop and high efficiency of separation (McCabe 1993, Kister 1992). For columns operating with higher vapour loads, trays may be more suitable and as such must be considered during the design phase. The design of a packed column can be performed through either the concept of transfer units or the evaluation of the height equivalent to theoretical plates (HETP) in combination with standard estimation of the number of required equilibrium stages. The number of equilibrium stages required can be determined through either graphical methods such as McCabe-Thiele or short-cut distillation column design methods such as the Fenske-Underwood-Gilliland (FUG) method. Further evaluation of a packed columns design can be performed using mass and heat transfer coefficients through non-equilibrium rate based models and is recommended for highly non-ideal, polar or reactive systems (Kister 1992). Additionally, simulation software, such as ASPEN HYSYS or ASPEN Plus may also be used for the design or evaluation of distillation systems.

The operating conditions of a MEG recovery column can vary depending upon the operating envelope of the individual distillation unit (AlHarooni et al. 2015). Some MEG recovery units operate at temperatures as low as $95^{\circ} \mathrm{C}$ (Diba, Guglielminetti, and Schiavo 2003), $140^{\circ} \mathrm{C}$ (Montazaud 2011) and up to temperatures of $160^{\circ} \mathrm{C}$ (Gonzalez, Alfonso, and Pellegrino 2000), with Psarrou et al (2011) recommending operation between $120^{\circ} \mathrm{C}$ to $160^{\circ} \mathrm{C}$ within the reboiler. Standard industrial operating practice for both the regeneration and reclamation process typically sees the operation of the MEG distillation column at atmospheric to vacuum pressures (Psarrou et al. 2011). The operating temperature and pressure of the reboiler depends highly on the temperature to which MEG will begin to experience thermal degradation. Under excessive temperatures, MEG may begin to break down to form organics acids including glycolic, acetic and formic acids (AlHarooni et al. 2015, Rossiter Jr et al. 1985) leading to higher operating costs through MEG makeup, impacts on system pH requiring additional adjustment and the potential increase in carbon steel corrosion through the presence of acetic acid (Ikeh, Enyi, and Nasr 2016, Dong, ZhenYu, and XingPeng 2008). To combat MEG thermal degradation, the reboiler may be operated at lower pressures to reduce the required temperature to achieve boiling in order to decrease the likelihood of the MEG degrading (AlHarooni et al. 2015).

In this study, the primary focus of investigation is the recovery of MEG from water at varying temperatures and feed concentrations under both batch and continuous operation at a fixed reflux ratio. A secondary investigation has then been performed to investigate the impact salts present within the rich MEG feed on the MEG regeneration process through analysis of experimental and simulated results. 


\subsection{Salt Precipitation within MEG Systems}

The prevention and mitigation of salt precipitation within process piping and equipment is a crucial aspect of effectively designing a MEG regeneration system. Typically, the most frequently encountered salts in MEG processing occur from the presence of the monovalent cations sodium, $\mathrm{Na}^{+}$potassium, $\mathrm{K}^{+}$and the divalent cations calcium, $\mathrm{Ca}^{2+}$ iron, $\mathrm{Fe}^{2+}$ and magnesium, $\mathrm{Mg}^{2+}$ (Latta et al. 2016, Babu et al. 2015). Within the confines of the MEG regeneration column, the primary impact of salt occurs due to the precipitation of the divalent salts, $\mathrm{CaCO}_{3}, \mathrm{FeCO}_{3}, \mathrm{FeS}$ and $\mathrm{Mg}(\mathrm{OH})_{2}$ within the columns internals and reboiler unit. Due to the high solubility of monovalent cations, they typically remain dissolved in the MEG solution by-passing the regeneration column only precipitating once reaching the downstream MEG reclamation unit (Latta et al. 2016).

In hydrocarbon gas processing, the participation of $\mathrm{CaCO}_{3}$ is considered to be one of the most frequently experienced sources of mineral precipitation and scaling (Flaten et al. 2015). The presence of $\mathrm{Ca}^{2+}$ in the MEG solution originates from the breakthrough of formation water during processing alongside $\mathrm{Mg}^{2+}$ and the previously mentioned monovalent cations. Conversely, the presence of $\mathrm{Fe}^{2+}$ within an MEG recovery system primarily stems from the development of an iron carbonate film upon the inside of piping for corrosion control and is such referred to as a corrosion product (Flaten, Seiersten, and Andreassen 2010). The precipitation of FeCO primarily occurs within 'sweet' systems with low $\mathrm{H}_{2} \mathrm{~S}$ content, however, the precipitation of FeS is possible when the $\mathrm{H}_{2} \mathrm{~S}$ concentration is sufficient (Figueiredo et al. 2015). As carbon steel piping is used in most if not all MEG recovery systems, pipeline corrosion products will always be present to some degree in both solid and dissolved forms. Alongside $\mathrm{CaCO}_{3}, \mathrm{FeCO}_{3}$ is one of the most abundant carbonates precipitating within MEG distillation systems (Latta et al. 2016, Figueiredo et al. 2015).

The effect of salt precipitation upon MEG regeneration columns is most prevalent within a columns reboiler unit and associated piping. The precipitation of divalent salts, in particular $\mathrm{CaCO}_{3}$ and $\mathrm{FeCO}_{3}$ is promoted by the high fraction of MEG in the bottom product (Latta et al. 2016). This effect is shown by the solubility studies performed by Kassa and co-workers who observed decreasing solubility of various salts in increasing MEG content solutions. The precipitation of salts within the columns reboiler can cause severe fouling and the accumulation of suspended solids in the lean MEG bottoms product (Latta et al. 2016). The overall influence of fouling may lead to the reduced heat transfer efficiency of the reboiler resulting in a poor separation of the MEG from water. The presence of iron sulphide within piping and MEG systems can cause major issues due to its ability to cause crevice or bimetallic corrosion in the presence of water (Smith and Miller 1975).

\subsection{Process Design and Configuration}

As shown by the process flow scheme in Figure 1, the distillation system is comprised of a feed pre-treatment section followed by a packed distillation column. Initially, a feed tank is used for the preparation of the MEG-Water solution using MEG supplied by Chem Supply Australia with the typical composition shown in Table 1 . Once prepared, the rich MEG feed is pumped through a filtration system to remove solid particulates and is subsequently measured by a mass flow meter (MFM) to monitor inlet flow. The MEG-Water feed to the column was maintained at $30^{\circ} \mathrm{C}, 140 \mathrm{kPa}$ at a mass flow rate of $6.5 \mathrm{~kg} /$ hour and fed directly into the re-boiler unit. Prior to operation, the MEG feed tank is blanketed with nitrogen gas to prevent oxygen ingress within the vessel.

The distillation system employs a $0.012 \mathrm{~m}^{3}$ glass re-boiler at the base of the column heated by a $5 \mathrm{~kW}$ insertion heater. The power of the re-boiler's heater is directly controlled by a programmable logical controller (PLC) to maintain the desired reboiler temperature during operation. The bottoms product of the re-boiler is removed through the MEG pump and the flow rate measured by a MFM, the product is then cooled by a plate heat exchanger operated using cooling water at $15^{\circ} \mathrm{C}$.

The main section of the distillation column itself is comprised of two individual sections, each one metre in height. The sections are connected and fitted with structural packing of diameter $80 \mathrm{~mm}$ DN (3"). The column operates with a pressure differential indicator and temperature gauge to monitor the conditions within the column during processing. The final section of the distillation system encapsulates the vapour condensation and reflux systems. The condenser unit acts as a total condenser and is operated using cool water provided by a chiller system at approximately $15^{\circ} \mathrm{C}$ with the flow rate of cooling water manually controlled. A glass reflux drum is located directly below the condenser unit to collect the liquid reflux by gravitationally induced flow. The reflux is then fed back 
into the distillation columns by pump and measured by a MFM, if required, a water product stream can also be operated during continuous operation.

Additional measurements are performed by means of $\mathrm{pH}, \mathrm{O}_{2}$ and conductivity probes located at the re-boiler and reflux product line. Further monitoring of the process is performed by level and pressure gauges installed in the locations shown by Figure 1, with an additional level sensor installed on the re-boiler unit.

\section{Table 1 - MEG Composition}

$\begin{array}{cc}\text { Minimum Assay (\%) } & 99.0 \% \\ \text { Water } & 0.5 \% \\ \text { Diethylene Glycol (DEG) } & 0.02 \% \\ \text { Ash Content } & 0.001 \% \\ \text { Acidity (as Acetic Acid) } & 0.001 \% \\ \text { Aldehyde (as Formaldehyde) } & 0.0008 \% \\ \text { Chlorine (Cl) } & 0.00001 \% \\ \text { Iron (Fe) } & 0.000005 \%\end{array}$

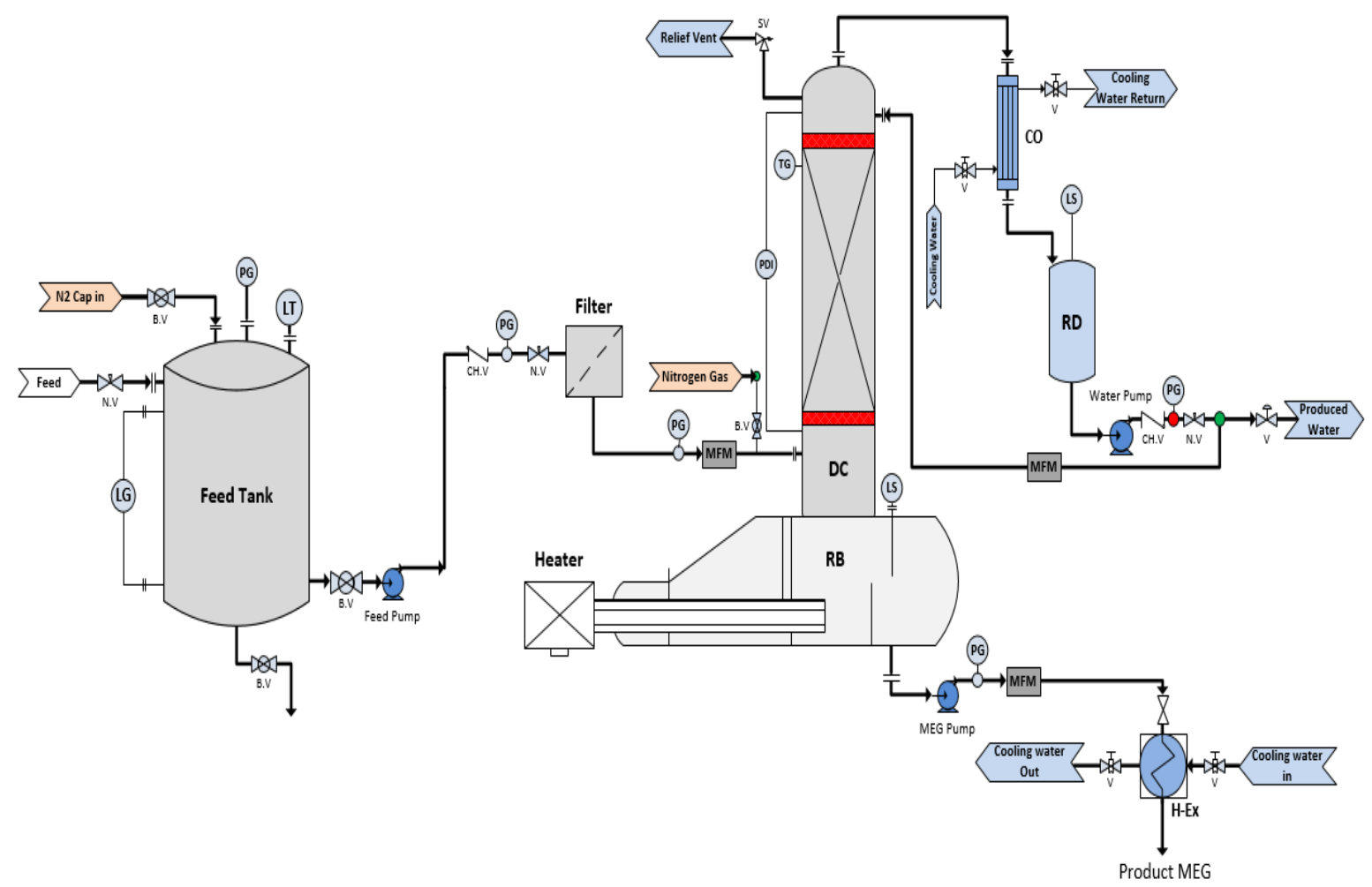

Figure 1: Flow Diagram for MEG Recovery System

\section{Table 2 - MEG Regeneration Flow Scheme Abbreviations}

\begin{tabular}{|c|c|c|c|c|c|c|c|}
\hline B.V & Ball Valve & LG & Level Gauge & \multirow{2}{*}{ PDI } & \multirow{2}{*}{$\begin{array}{l}\text { Pressure Differential } \\
\text { Indicator }\end{array}$} & SV & Safety Valve \\
\hline $\mathrm{CH} . \mathrm{V}$ & Check Valve & LS & Level Sensor & & & TG & Temperature Gauge \\
\hline $\mathrm{CO}$ & Total Condenser & LT & Level Transmitter & PG & Pressure Gauge & V & Valve \\
\hline DC & Distillation Column & MFM & Mass Flow Meter & RB & Reboiler & & \\
\hline H-Ex & Heat Exchanger & N.V & Needle Valve & $\mathrm{RD}$ & Reflux Drum & & \\
\hline
\end{tabular}




\subsection{Equipment Used}

The separation of MEG from water was performed using a structurally packed distillation column constructed by De Dietrich Process Systems GmbH, Germany, (De Dietrich) for MEG processing, based upon specifications developed by the Curtin Corrosion Engineering Industry Centre (CCEIC). The operating conditions and design specifications of the MEG distillation column are summarised in Table 3. The distillation column operates using Durapack borosilicate glass 3.3 structured packing provided by De Dietrich, such packing was chosen for its high mass transfer efficiency. Table 4 outlines the specifications and dimensions of the structured packing.

Partial vaporisation of the bottoms product was performed using a kettle type glass reboiler designed for a liquid volume capacity of eight litres. Operation of the reboiler unit was maintained at $130 \mathrm{kPa}$ throughout distillation, with the unit operated within a temperature range of $120^{\circ} \mathrm{C}$ up to $160^{\circ} \mathrm{C}$. Operation of the reboiler unit at temperatures above $160^{\circ} \mathrm{C}$ was not performed due to the possibility of thermal degradation effects of MEG at temperatures reaching its boiling point with a temperature limiter was installed as a safety measure to prevent operation at temperatures above $160^{\circ} \mathrm{C}$. Furthermore, the total condenser unit operates in conjunction with a 5 litre capacity reflux drum to provide liquid reflux to the column.

The distillation system was operated using magnetic drive gear pump systems manufactured by Micropump for the feed, bottom and reflux product pumps. The Micropump L15034 pump was employed for pumping of the feed stream with a total capacity of $6.5 \mathrm{~kg} / \mathrm{hr}$. Conversely, the reflux and bottom product pumps were designed for a maximum capacity of $4 \mathrm{~kg} / \mathrm{hr}$ using the L21382 Micropump system. The composition of the MEGWater solution in the feed, distillate and bottom products was measured using an ATAGO PAL-91S refractometer shown in Figure 2. The refractometer measures the MEG concentration within a $0-90 \%$ concentration range with an accuracy of $\pm 0.4 \%$ $(\mathrm{V} / \mathrm{V})$ based upon the refractive index of the solution. The mass flow rate of each stream was measured by Promass A100 inline mass flow metres manufactured by Endress+Hauser with an accuracy of $\pm 0.1 \%$.

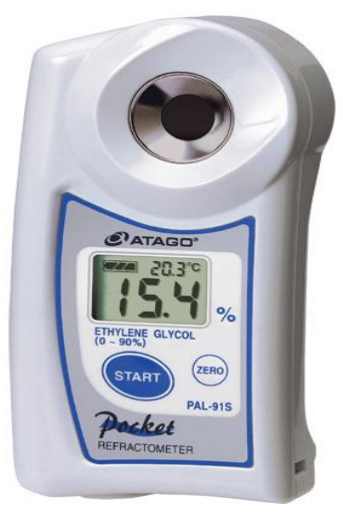

Figure 2: ATAGO Refractometer (ATAGO)

\section{Table 3 - Distillation Column Specifications}

$$
\begin{gathered}
\text { Feed Rate } \\
\text { Feed Conditions } \\
\text { Column Design Operating Pressure } \\
\text { Distillation Design Temperature } \\
\text { Condenser Type } \\
\text { Reflux Drum (Capacity/Pressure) } \\
\text { Reboiler (Capacity/Pressure) } \\
\text { Reboiler Power requirements } \\
\text { Column Diameter } \\
\text { Packing height } \\
\text { Packing material }
\end{gathered}
$$

Up to $6.5 \mathrm{Kg} / \mathrm{hr}$.

Temperature: $30^{\circ} \mathrm{C}$, Pressure: $140 \mathrm{kPa}$

$$
\begin{gathered}
100-150 \mathrm{kPa} \\
20-150{ }^{\circ} \mathrm{C} \\
\text { Total }
\end{gathered}
$$

$$
0.005 \mathrm{~m}^{3} / 120 \mathrm{kPa}
$$

Kettle type $\left(0.008 \mathrm{~m}^{3} / 130 \mathrm{kPa}\right)$

$$
5 \mathrm{~kW}
$$

DN $80(76.2 \mathrm{~mm})$

$900 \mathrm{~mm} \times 2$ Sections

Borosilicate glass 3.3 Structured Packing

Table 4 - Packing Specifications

$\begin{array}{cc}\text { Packing Surface Area } & 300.0 \mathrm{~m}^{2} / \mathrm{m}^{3} \\ \text { Packing Factor, } F_{P} & 195.3 \mathrm{~m}^{2} / \mathrm{m}^{3} \\ \text { Packing Void Fraction } & 0.824 \\ \text { Corrugation Base Width } & 1.8856 \mathrm{~cm} \\ \text { Corrugation Side Dimension } & 1.3333 \mathrm{~cm} \\ \text { Corrugation Height } & 0.94281 \mathrm{~cm} \\ \text { Corrugation Angle } & 45^{\circ}\end{array}$


The pressures of each stream were measured using steel pressure gauges, with tantalum membranes capable of operating between $-50^{\circ} \mathrm{C}$ and $200^{\circ} \mathrm{C}$. The pressure within the reflux drum was monitored using a Cerabar PMC71 digital pressure transmitter manufactured by Endress+Hauser. The pressure transmitter is capable of operating in process temperature ranges of $-40^{\circ} \mathrm{C}$ to $150^{\circ} \mathrm{C}$ and up to $4000 \mathrm{kPa}$ with an accuracy of $\pm 0.075 \%$. A Deltabar PMD75 was used to measure the differential pressure of the distillation column capable of operating between $-40^{\circ} \mathrm{C}$ to $85^{\circ} \mathrm{C}$ and 0.025 to $4000 \mathrm{kPa}$ with an accuracy of $\pm 0.05 \%$.

The top operating temperature within the distillation column was measured using a WIKA model 55 bimetal thermometer installed at the top of the column. The thermometer can measure temperatures within $-70^{\circ} \mathrm{C}$ to $600^{\circ} \mathrm{C}$ with an accuracy of $\pm 1^{\circ} \mathrm{C}$. The liquid level within the reboiler was monitored using an Endress + Hauser level detection Liquiphant FTL51 system utilising 316L stainless steel as the sensor material. The unit can operate between $-50^{\circ} \mathrm{C}$ to $150^{\circ} \mathrm{C}$ and up to $10 \mathrm{mPa}$. Additional measurements including $\mathrm{pH}$, oxygen content and electrical conductivity of the rich MEG were taken during operation. $\mathrm{pH}$ measurements are made using a Mettler Toledo InPro 4800 pH sensor. Dissolved oxygen was measured using a Mettler Toledo 6510i dissolved ozone sensor with an operating range of $0-5000 \mathrm{ppb}(\mathrm{mg} / \mathrm{L})$ and an accuracy of $+/-4 \%$ or $3 \mathrm{ppb}$. Finally, the conductivity of solution was measured using an InPro 7100 conductivity meter capable of operating between $-20^{\circ} \mathrm{C}$ to $150{ }^{\circ} \mathrm{C}$

\subsection{Construction}

The assembly of the distillation column used in the recovery of MEG from water was performed by the CCEIC and commenced on May 2015. The main experimental systems of the project were specified by CCEIC; designed and manufactured by De Dietrich and consisted of the equipment outlined by Table 5 . The construction and installation of the distillation column and its subsystems was performed according to the following procedure with an image of the completed distillation column shown in Figure 3:

1. Preparation of the foundation base and Installation of the structural frame.

2. Re-boiler vessel preparation and setup of the liquid level measurement device and thermometer cable.

3. Installation of the first section of column fitting of the first five layers of structured packing.

4. Installation of the second column section on top of the first using a glass joint of $200 \mathrm{~mm}$ in length.

5. Installation of the bimetal thermometer at the top of second column.

6. Connection of the second column to the condenser unit by a T-connection, the first end is connected to the relief valve and the second is connected to the condenser unit.

7. Installation of the thermometer cable at the top of condenser.

8. Connection of the condenser unit to the Reflex drum by Polytetrafluoroethylene (PTFE) bellows.

9. Installation of the process pressure gauge, normal pressure gauge and level gauge to the Reflex drum.

10. Installation of the differential pressure gauge that connects the first vent to the bottom of the first column section and from the second vent to the top of the system.

11. Installation of additional column supports anchored to the structural frame to provide support when removing or replacing system components.

12. Installation of the distillation column control system for controlling of the reboiler temperature.

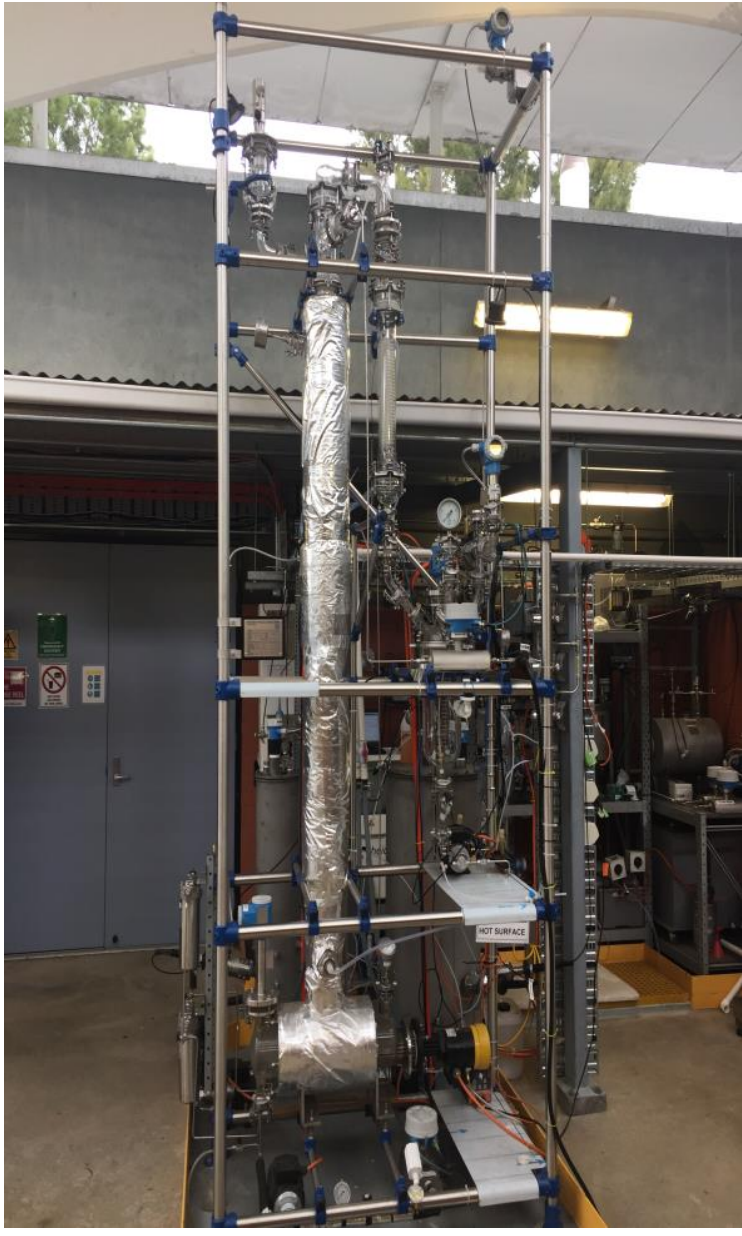

Figure 3: MEG Distillation Column 
Table 5 - Equipment supplied by QVC

Main distillation system components

Carbon steel frame structure $(3618 \mathrm{~mm}$ height, $1250 \mathrm{~mm}$ width, $685 \mathrm{~mm}$ length)

Re-boiler vessel

Re-boiler vessel heating unit

Two glass columns to be connected in series

Relief valve set at $150 \mathrm{kPag}$

Condenser unit and reflux drum

Feed, reflux and bottom product pumps
Rich MEG tank

Lean MEG tank

Measurement Systems

Differential pressure gauge

Process stream pressure gauges

Reboiler liquid level measurement system

Bi-metal thermometer - stainless steel

Two vessel pressure gauges.

Solid filtration system

\subsection{Operating Procedure}

Experimental trials were performed for both batch and continuous operation of the distillation column for varying mass fractions of MEG within the feed and varying reboiler operating temperatures. Prior to operation, the system was flushed with distilled water to clean any residual solution from previous trials and Continuous sparging with high purity nitrogen $(99.995 \%, \mathrm{BOC})$ ensured minimum oxygen ingress. Operation of the column for both batch and continuous distillation operation was conducted as follows.

During batch operation, the distillation system was prepared by filling the re-boiler and reflux drum with the MEG-Water solution at the desired concentrations shown in Table 6. For each run performed, eight kilograms of the MEG-Water solution was introduced in to the re-boiler, while two kilograms of the solution was introduced into the reflux drum. Once filling of the re-boiler and reflux drum had been completed, the re-boilers heating element was initiated. On the first occurrence of vapour evolving from the heated solution, operation of the reflux pump was commenced. The reflux drum was operated under total reflux mode with no product withdrawal to circulate the solution until the desired reboiler temperature, as per Table 6 was achieved. The release of the first bubbles are an indication that the unsteady state operation of the column has commenced.

Typically, total reflux circulation was performed for two to three hours until the distillation system had reached steady state mode. Steady state conditions are normally achieved when the re-boiler temperature reaches between $125-145^{\circ} \mathrm{C}$, as shown in the Table 6 and Figure 6 . Operation of the column under total reflux is performed with the condenser unit operating at a constant $15^{\circ} \mathrm{C}$. The condenser is maintained at such temperature by cooling water supplied by a chiller unit operating at $15^{\circ} \mathrm{C}$.

Sampling from the reboiler and the reflux drum sections were taken at 30 minute intervals to measure the MEG concentrations using the ATAGO refractometer. The concentration of MEG over time was used to determine the time required to reach steady state operation of the distillation column. Once steady state conditions had been achieved indicated by the stabilisation of reboiler and reflux drum MEG concentrations operation of the column was ceased.

In a similar manner to batch distillation, operation of the distillation column using continuous operation was prepared by introducing eight kilograms of the MEG-Water solution at the required concentration from the rich MEG feed tank into the reboiler. The reboiler heater was then started while the reflux drum was filled with two kilograms of distilled water. Upon the evolution of vapour from the liquid within the reboiler, the reflux drum circulation rate was set at three kilograms per hour. The column operated under total reflux conditions until the reboiler operating temperature stabilised and steady state conditions were achieved. The feed was then introduced into the columns reboiler at the flow rates shown in Table 6 and Table 7 for each case. Operation of the column then proceeded at the respective reflux ratios. The sampling of reboiler and reflux drum compositions were regularly taken and tested by ATAGO refractometer in a similar manner to the batch operation. Overall, trials were conducted to evaluate the impact of changing reboiler temperature and feed mass fraction on mass fraction of MEG within the bottoms product. 


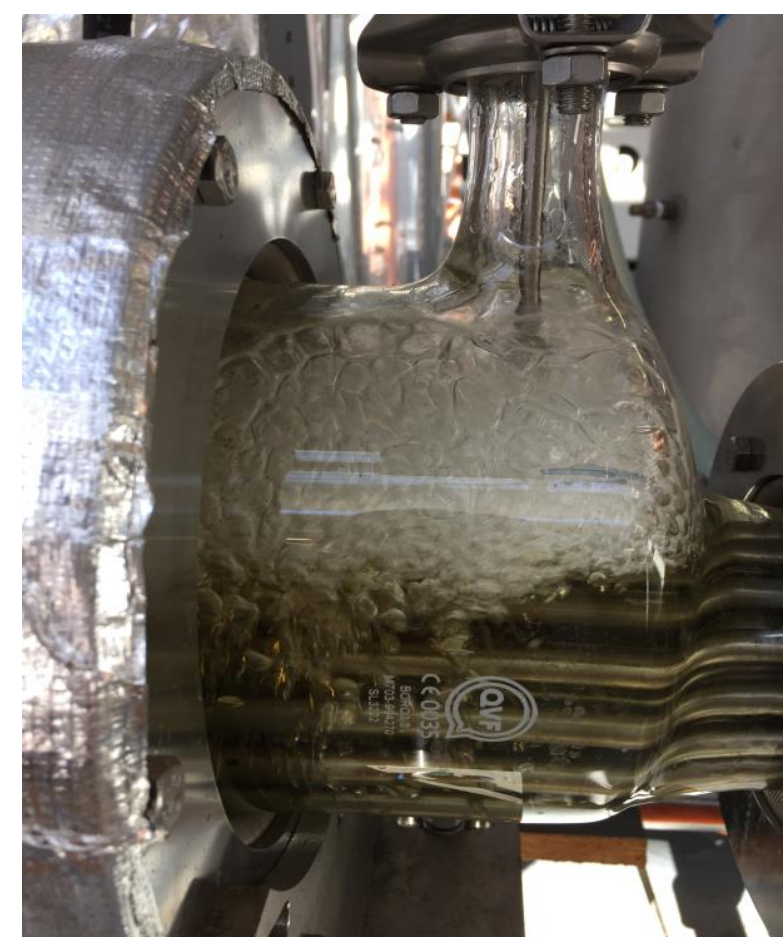

Figure 4: MEG Distillation Column Reboiler

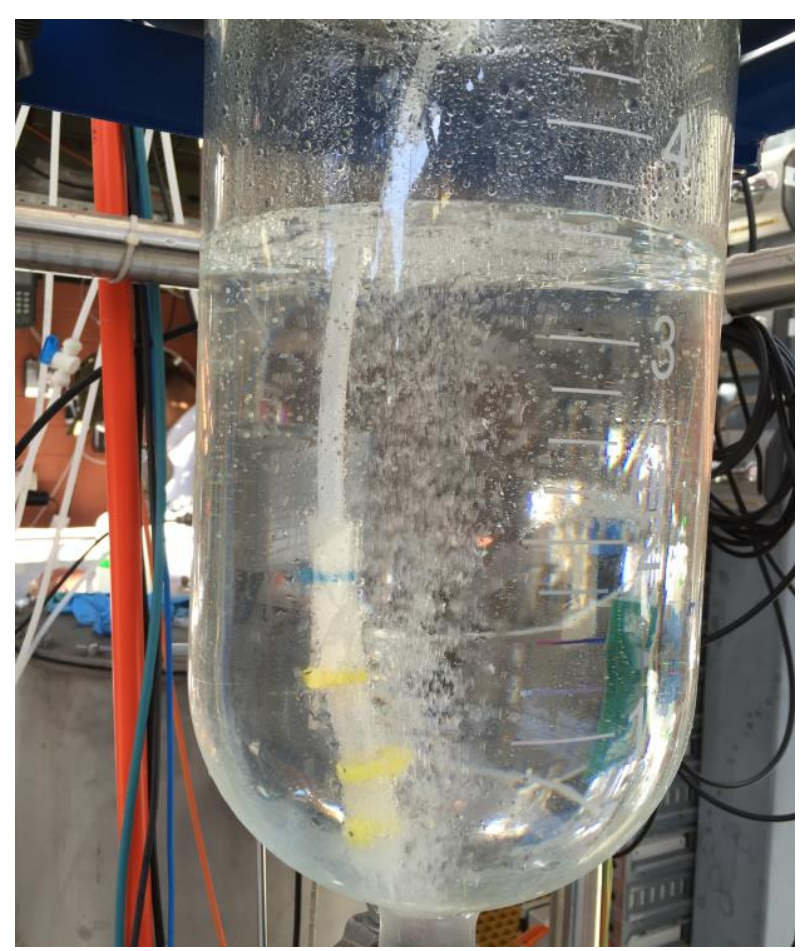

Figure 5: MEG Distillation Column Reflux Vessel

\subsection{Operating Results and Calculations}

Operating results of sixteen trials utilising both batch and continuous operation are summarised in Table 6 and Table 7. Analysis of the results was conducted using the McCabe-Thiele graphical method in conjunction with the Fenske-Underwood-Gilliland short cut distillation column design equations to determine the number of stages required to achieve the experimental separations. As results were recorded in mass fractions they were first converted to mole fractions for the purpose of estimating the number of stages by both methods. Figures 8 to 10 present the McCabe Thiele diagrams for Trials (1), (6) and (16) respectively. In addition, the concepts of transfer units and HETP were used to further evaluate the efficiency of the columns packing with the methodology utilised discussed in the subsequent section. A summary of the analysis performed can be found in Table 9 for batch and Table 10 for continuous experimental trials. Figure 6, illustrates the operation of the column during batch operation for Trials (1) and (2), it was observed that the system reached equilibrium typically within 60 minutes.

In order to construct the McCabe-Thiele graphical diagrams, an estimation of the Vapour Liquid Equilibrium (VLE) curve of the MEG-Water binary system was required. Estimation of the curve was performed using partial pressures derived from Antoine coefficients for both water and MEG over the operating temperature of the column. A comparison was also made to literary sources of VLE data and is graphically represented in Figure 7. It can be observed that the calculated VLE curve is lower than that of many sources of VLE data, the difference can be attributed to the higher operating temperatures of the column compared to the test conditions the VLE data was obtained at. However, the calculated VLE curve closely matches the data of Trimble and Potts (1935) where the data was derived at a similar pressure.

The operation of the ATAGO refractometer in measuring the MEG mass concentration within the reflux drum was limited to $100 \mathrm{ppm}$. Therefore, the lower concentrations experienced during continuous operation recorded a concentration of zero, as such, a value of minimum value of $100 \mathrm{ppm}$ was used in analysis of the continuous trials. 
Table 6 - Batch and Continuous Operating Conditions and Product Compositions Salt Free Trials

\begin{tabular}{|c|c|c|c|c|c|c|c|}
\hline $\begin{array}{l}\text { Trial } \\
\text { No. }\end{array}$ & $\begin{array}{l}\text { Column } \\
\text { Operation } \\
\text { Type }\end{array}$ & $\begin{array}{c}\text { Reboiler } \\
\text { Temperature } \\
\text { (K) }\end{array}$ & $\begin{array}{l}\text { MEG Feed } \\
\text { Mass } \\
\text { Fraction }\end{array}$ & $\begin{array}{l}\text { Feed Flow } \\
\text { Rate } \\
(\mathrm{kg} / \mathrm{hr})\end{array}$ & $\begin{array}{l}\text { Reflux } \\
\text { Ratio }\end{array}$ & $\begin{array}{l}\text { Reboiler } \\
\text { MEG Mass } \\
\text { Fraction }\end{array}$ & $\begin{array}{c}\text { Reflux Drum MEG } \\
\text { Concentration } \\
\text { (ppm) }\end{array}$ \\
\hline (1) & Batch & $135^{\circ} \mathrm{C}$ & 0.55 & - & Total & 0.820 & 1500 \\
\hline (2) & Batch & $140^{\circ} \mathrm{C}$ & 0.65 & - & Total & 0.860 & 2000 \\
\hline (3) & Continuous & $130^{\circ} \mathrm{C}$ & 0.5 & 5 & 0.44 & 0.776 & $<100$ \\
\hline (4) & Continuous & $135^{\circ} \mathrm{C}$ & 0.50 & 5 & 0.52 & 0.834 & $<100$ \\
\hline (5) & Continuous & $137^{\circ} \mathrm{C}$ & 0.5 & 5 & 0.52 & 0.848 & $<100$ \\
\hline (6) & Continuous & $140^{\circ} \mathrm{C}$ & 0.50 & 5 & 0.44 & 0.864 & $<100$ \\
\hline (7) & Continuous & $141^{\circ} \mathrm{C}$ & 0.65 & 6 & 0.51 & 0.860 & $<100$ \\
\hline (8) & Continuous & $142^{\circ} \mathrm{C}$ & 0.45 & 5 & 0.33 & 0.868 & $<100$ \\
\hline (9) & Continuous & $145^{\circ} \mathrm{C}$ & 0.5 & 5 & 0.44 & 0.876 & $<100$ \\
\hline
\end{tabular}

Table 7 - Continuous Operating Conditions and Product Compositions Dissolved Salt Trials

\begin{tabular}{lcccccc}
$\begin{array}{c}\text { Trial } \\
\text { No. }\end{array}$ & $\begin{array}{c}\text { Reboiler } \\
\text { Temperature (K) }\end{array}$ & $\begin{array}{c}\text { MEG Feed } \\
\text { Mass Fraction }\end{array}$ & $\begin{array}{c}\text { Feed Flow } \\
\text { Rate }(\mathrm{kg} / \mathrm{hr})\end{array}$ & $\begin{array}{c}\text { Reflux } \\
\text { Ratio }\end{array}$ & $\begin{array}{c}\text { Reboiler MEG Mass } \\
\text { Fraction }\end{array}$ & $\begin{array}{c}\text { Reflux Drum MEG } \\
\text { Concentration (ppm) }\end{array}$ \\
$(10)$ & $130^{\circ} \mathrm{C}$ & 0.675 & 5.24 & 0.50 & 0.740 & $<100$ \\
$(11)$ & $130^{\circ} \mathrm{C}$ & 0.65 & 5.0 & 0.50 & 0.720 & $<100$ \\
$(12)$ & $135^{\circ} \mathrm{C}$ & 0.715 & 5.0 & 0.50 & 0.750 & $<100$ \\
$(13)$ & $135^{\circ} \mathrm{C}$ & 0.71 & 5.3 & 0.50 & 0.780 & $<100$ \\
$(14)$ & $135^{\circ} \mathrm{C}$ & 0.70 & 5.0 & 0.50 & 0.750 & $<100$ \\
$(15)$ & $135^{\circ} \mathrm{C}$ & 0.74 & 5.0 & 0.50 & 0.770 & $<100$ \\
$(16)$ & $140^{\circ} \mathrm{C}$ & 0.73 & 5.3 & 0.51 & 0.800 & \\
\hline
\end{tabular}

\section{Table 8 - Salt Trial Dissolved Salt Compositions Within Reboiler}

$\begin{array}{cccccccc}\begin{array}{c}\text { Dissolved } \\ \text { Salts (ppm) }\end{array} & (10) & (11) & (12) & (13) & (14) & (15) & (16) \\ \mathrm{Na}^{+} & 8744 & 8804 & 8021 & 7819 & 8281 & 7243 & 6695 \\ \mathrm{~K}^{+} & 3090 & 2715 & 2909 & 3213 & 3121 & 2813 & 2645 \\ \mathrm{Ca}^{2+} & 2.9 & 3.5 & 3.88 & 163 & 19.8 & 2.3 & 99 \\ \mathrm{Mg}^{2+} & - & - & 0.233 & 0.647 & - & - & - \\ \mathrm{Fe}^{3+} & 0.346 & 0.445 & 0.347 & 0.109 & 0.255 & 0.43 & 0.127 \\ \mathrm{Sr}^{2+} & 0.011 & 0.013 & - & 0.243 & 0.044 & 0.024 & 0.237 \\ \mathrm{Ba}^{2+} & 0.504 & 0.367 & 0.273 & 0.574 & 0.452 & 0.295 & 0.615\end{array}$




\section{Reboiler MEG Concentration vs. Time}

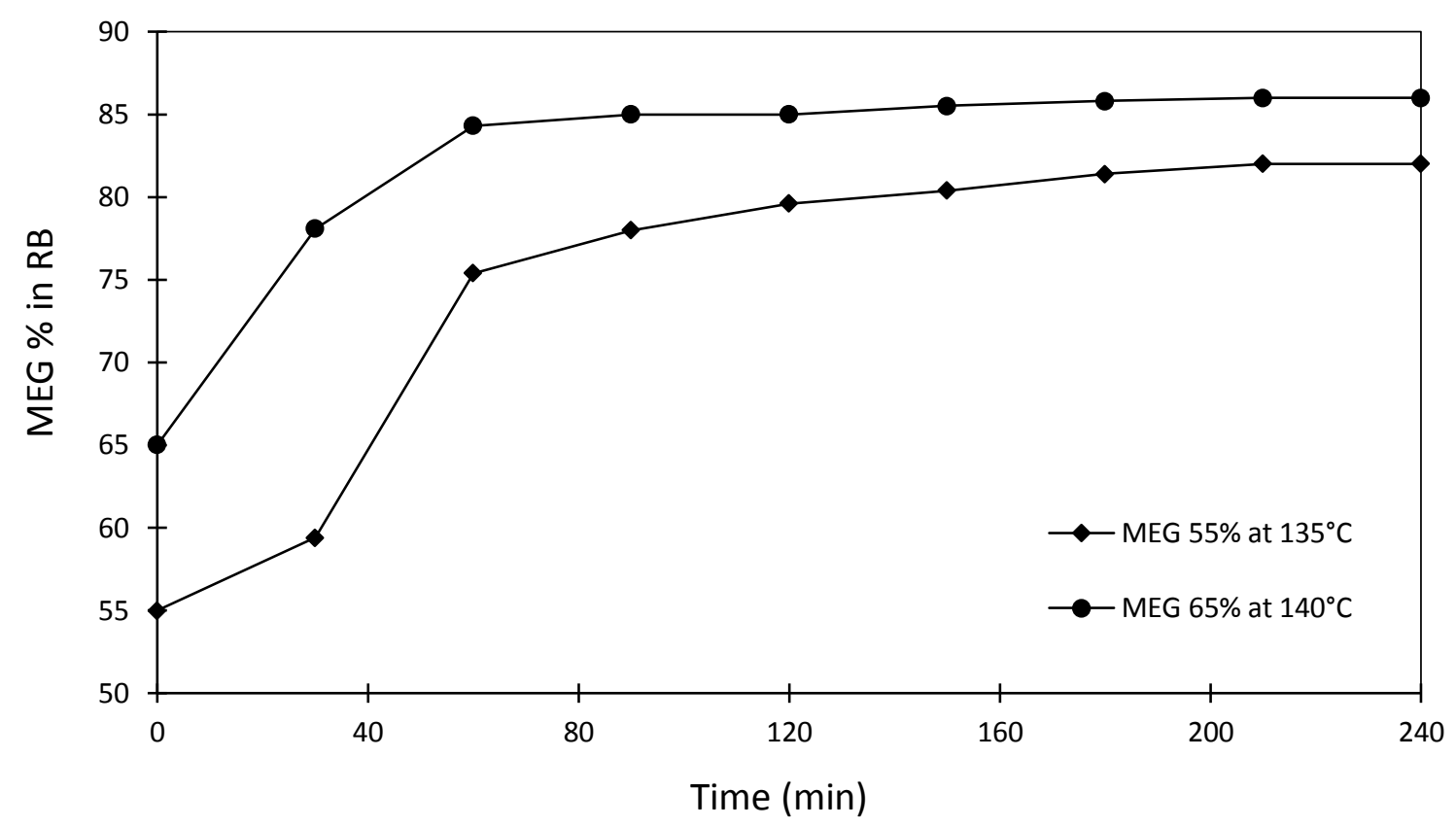

Figure 6: Batch Reboiler MEG Concentration Over Time

\subsection{Calculation Equations and Methodology}

The required number of stages for each trial experiment was estimated using the Fenske-Underwood-Gilliland (FUG) shortcut design equations. Initially, the minimum number of stages required to achieve a given separation was estimated using the Fenske equation given by Equation (1). For trials one and two, operating under batch conditions the minimum number of stages given by the Fenske equation represent the actual number of stages required.

$$
\mathrm{N}_{\text {min }}=\frac{\ln \left[\left(\frac{\mathrm{x}_{\mathrm{A}}}{\mathrm{x}_{\mathrm{B}}}\right)_{\text {dist }}\left(\frac{\mathrm{X}_{\mathrm{B}}}{\mathrm{x}_{\mathrm{A}}}\right)_{\text {bot }}\right]}{\ln \alpha_{\mathrm{AB}}}
$$

Due to the binary nature of the MEG-Water system, estimation of the minimum reflux ratio by the multicomponent system Underwood equations was unnecessary. Instead, the minimum reflux was estimated by Equation (2) of which is derived from the Underwood minimum reflux equations for binary systems where the liquid feed fraction is equal to one.

$$
\mathrm{R}_{\min }=\frac{1}{\alpha-1}\left[\frac{\mathrm{x}_{\mathrm{D}}}{\mathrm{x}_{\mathrm{F}}}-\alpha\left(\frac{1-\mathrm{x}_{\mathrm{D}}}{1-\mathrm{x}_{\mathrm{F}}}\right)\right]
$$

The estimation of the actual number of stages required at a finite reflux was performed using the Gilliland correlation in the form of the modified Molokanov et al. (1971) equation. Molokanov's correlation is represented by Equation (3).

$$
\begin{aligned}
\frac{\mathrm{N}-\mathrm{N}_{\min }}{\mathrm{N}+1} & =1-\exp \left[\left(\frac{1+54.4 \psi}{11+117.2 \psi}\right)\left(\frac{\psi-1}{\psi^{0,5}}\right)\right] \\
\Psi & =\frac{\mathrm{R}-\mathrm{R}_{\min }}{\mathrm{R}+1}
\end{aligned}
$$

The number and height of transfer units were estimated to provide a secondary estimation of the packed columns performance. The number of transfer units (NTU) required represents the difficulty of the separation whereas the height of transfer units (HTU) is a measure of the effectiveness of the packing (Coker 2010). 
Estimation of the number of transfer units for each trial was performed using Equation (4) and evaluated using numerical integration by the Simpson's rule.

$$
\mathrm{NTU}=\int_{\mathrm{yB}}^{\mathrm{yD}} \frac{\mathrm{dy}}{\mathrm{y}^{*}-\mathrm{y}}
$$

As described by Dutta (2007), the mass transfer exchange between the vapour and liquid phases in distillation is primarily controlled by the vapour phase resistance. As such, the estimation of the HTU was conducted based upon the overall height of the gas phase transfer unit, $\mathrm{H}_{\mathrm{OG}}$ as per Equation (6). The gas and liquid phase transfer units, $\mathrm{H}_{\mathrm{G}}$ and $\mathrm{H}_{\mathrm{L}}$ can be evaluated from the individual mass transfer coefficients of the gas and liquid phases, $\mathrm{k}_{\mathrm{G}}$ and $\mathrm{k}_{\mathrm{L}}$ respectively and the effective interfacial area of packing, $\mathrm{a}_{\mathrm{e}}$ through Equations (6) and (7).

$$
\begin{gathered}
\mathrm{H}_{\mathrm{OG}}=\mathrm{H}_{\mathrm{G}}+\lambda \mathrm{H}_{\mathrm{L}} \\
\mathrm{H}_{\mathrm{G}}=\frac{\mathrm{u}_{\mathrm{g}}}{\mathrm{k}_{\mathrm{G}} \mathrm{a}_{\mathrm{e}}} \\
\mathrm{H}_{\mathrm{L}}=\frac{\mathrm{u}_{\mathrm{L}}}{\mathrm{k}_{\mathrm{L}} \mathrm{a}_{\mathrm{e}}} \\
\lambda=\mathrm{m} \frac{\mathrm{G}_{\mathrm{m}}}{\mathrm{L}_{\mathrm{m}}}
\end{gathered}
$$

The height equivalent to a theoretical plate (HETP) represents a correlating factor between the height of packing required and the estimated number of theoretical stages necessary to achieve a desired separation (Coker 2010). The concept of HETP is used during column design to allow comparison of efficiencies between packed and plate columns, and is defined by Equation (9). Alternately, the HETP can be estimated from experimental results through the $\mathrm{H}_{\mathrm{OG}}$ by application of Equations (10) or (11).

$$
\begin{gathered}
\text { HETP }=\mathrm{Z} / \mathrm{N} \\
\text { HETP }=\frac{\mathrm{H}_{\mathrm{OG}} \cdot \ln \left(\mathrm{m} \frac{\mathrm{G}_{\mathrm{m}}}{\mathrm{L}_{\mathrm{m}}}\right)}{\mathrm{m}_{\frac{\mathrm{L}_{\mathrm{m}}}{\mathrm{L}_{\mathrm{m}}}-1}}=\mathrm{H}_{\mathrm{OG}} \cdot \frac{\ln \lambda}{\lambda-1} \text { for } \lambda \neq 1 \\
\mathrm{HETP}=\mathrm{H}_{\mathrm{OG}} \text { for } \lambda=1
\end{gathered}
$$

In order to determine gas phase transfer unit $\mathrm{H}_{\mathrm{OG}}$, initial estimation of the gas and liquid phase mass transfer coefficients was required. Estimation was performed using the mass transfer correlations developed by Bravo, Rocha, and Fair (1985) for gauze type structured packing due to its applicability to the structured packing utilised during distillation. Furthermore, the more simplistic nature of the correlations developed by Bravo, Rocha, and Fair (1985) compared to newer correlations as outlined by Wang, Yuan, and Yu (2005) was considered favourable. The gas and liquid phase mass transfer coefficient correlations utilised are outlined by Equations (12) and (13) respectively.

$$
\begin{gathered}
\mathrm{k}_{\mathrm{G}}=0.0338 \frac{\mathrm{D}_{\mathrm{G}}}{\mathrm{d}_{\mathrm{eq}}}\left[\frac{\rho_{\mathrm{g}} \mathrm{d}_{\mathrm{eq}}\left(\mathrm{u}_{\mathrm{Le}}+\mathrm{u}_{\mathrm{Ge}}\right)}{\mu_{\mathrm{G}}}\right]^{0.8} \mathrm{Sc}_{\mathrm{G}}^{0.33} \\
\mathrm{k}_{\mathrm{L}}=2 \sqrt{\frac{\mathrm{D}_{\mathrm{L}}}{\pi \mathrm{s}}\left(\frac{9 \Gamma^{2} \mathrm{~g}}{8 \rho_{\mathrm{L}} \mu_{\mathrm{L}}}\right)^{\frac{1}{3}}} \\
\mathrm{u}_{\mathrm{Ge}}=\frac{\mathrm{u}_{\mathrm{G}}}{\epsilon \sin \alpha} \\
\mathrm{u}_{\mathrm{Le}}=\left(\frac{9 \Gamma^{2} \mathrm{~g}}{8 \rho_{\mathrm{L}} \mu_{\mathrm{L}}}\right)^{\frac{1}{3}}
\end{gathered}
$$


Additional correlations developed by Wilke and Chang (1955) and Chapman (1970) were utilised in estimation of the liquid and gas phase diffusion coefficients respectively. The liquid phase diffusion coefficient, $\mathrm{D}_{\mathrm{L}}$ was estimated through Equation (17) utilising an association parameter assumed equal to that of ethanol of 1.5. The gas phase diffusion coefficient, $\mathrm{D}_{\mathrm{G}}$ was estimated through Equation (16) with the collision integral, $\Omega$ estimated through Equation (18) using the corresponding collision integrals reported by Cussler (1997). Equation (18) was evaluated using the Lennard-Jones potential parameters reported by Cussler (1997) and Ben-Amotz and Herschbach (1990) for water and ethylene glycol respectively. The average collision diameter, $\sigma_{12}$ calculated through Equation (19) was evaluated using the particle sizes reported by Cussler (1997) and Ben-Amotz and Herschbach (1990) for water and ethylene glycol respectively.

$$
\begin{gathered}
\mathrm{D}_{\mathrm{G}}=1.86 \times \frac{10^{-3} \mathrm{~T}^{\frac{3}{2}}\left(\frac{\mathrm{M}_{1}+\mathrm{M}_{2}}{\mathrm{M}_{1} \mathrm{M}_{2}}\right)^{\frac{1}{2}}}{\mathrm{P} \sigma_{12}^{2} \Omega} \\
\mathrm{D}_{\mathrm{L}}=\frac{7.4 \times 10^{-8}\left(\sqrt{\phi_{2} \mathrm{M}_{2}}\right) \mathrm{T}}{\mu_{2} \mathrm{~V}_{1}^{0.6}} \\
\frac{\varepsilon_{12}}{\mathrm{k}_{\mathrm{B}} \mathrm{T}}=\frac{\sqrt{\left(\frac{\varepsilon_{1}}{\mathrm{k}_{\mathrm{B}}}\right)\left(\frac{\varepsilon_{2}}{\mathrm{k}_{\mathrm{B}}}\right)}}{\mathrm{T}\left({ }^{\circ} \mathrm{K}\right)} \\
\sigma_{12}=\frac{1}{2}\left(\sigma_{1}+\sigma_{2}\right)
\end{gathered}
$$

The effective interfacial area provided by the packing utilised within the distillation column was estimated using the simple correlation proposed by Bravo and Fair (1990) given by Equation (20). The interfacial area was estimated assuming a flood percentage, $\mathrm{F}_{\mathrm{r}}$ less than $85 \%$ based upon the packing surface area, $\mathrm{a}_{\mathrm{p}}$ provided in Table 4.

$$
\frac{\mathrm{a}_{\mathrm{e}}}{\mathrm{a}_{\mathrm{p}}}=0.50+0.0058 \quad\left(\mathrm{~F}_{\mathrm{r}} \leq 0.85\right)
$$

\section{Table 9 - Analysis Summary of Batch Operation}

McCabe-Thiele

Trial No.

(2)
Number of Theoretical Stages

(1) 3

3
Number of Theoretical Plates

\section{FUG Method}

Number of Theoretical Number of Theoretical Stages Plates

2

$2.223(3)$

2

2

$2.240(3)$

2

\section{Table 10 - Analysis Summary of Continuous Operation}

McCabe-Thiele

Trial No.

(4)

(6)

(7)

(13)

(16)

$\begin{array}{cc}\text { Number of } & \text { Number of } \\ \text { Theoretical } & \text { Theoretical } \\ \text { Stages } & \text { Plates }\end{array}$

$$
4
$$

5

5

4

4
FUG Method

Number of Theoretical Stages

$5.325(6)$

$5.762(6)$

$5.516(6)$

$5.332(6)$

$5.395(6)$
Number of Theoretical Plates

\section{5}

5

5

5

5
Transfer Units

HETP

NTU HTU HETP HETP $(m)$

(m) $\quad(\mathrm{m}) \quad$ Estimated

$\begin{array}{lll}7.374 & 0.308 & 0.360\end{array}$

0.346

$\begin{array}{lll}6.169 & 0.308 & 0.360\end{array}$

0.329

$\begin{array}{lll}6.351 & 0.302 & 0.360\end{array}$

0.338

$\begin{array}{lll}6.310 & 0.229 & 0.360\end{array}$

0.254

$\begin{array}{lll}6.360 & 0.217 & 0.360\end{array}$

0.241 


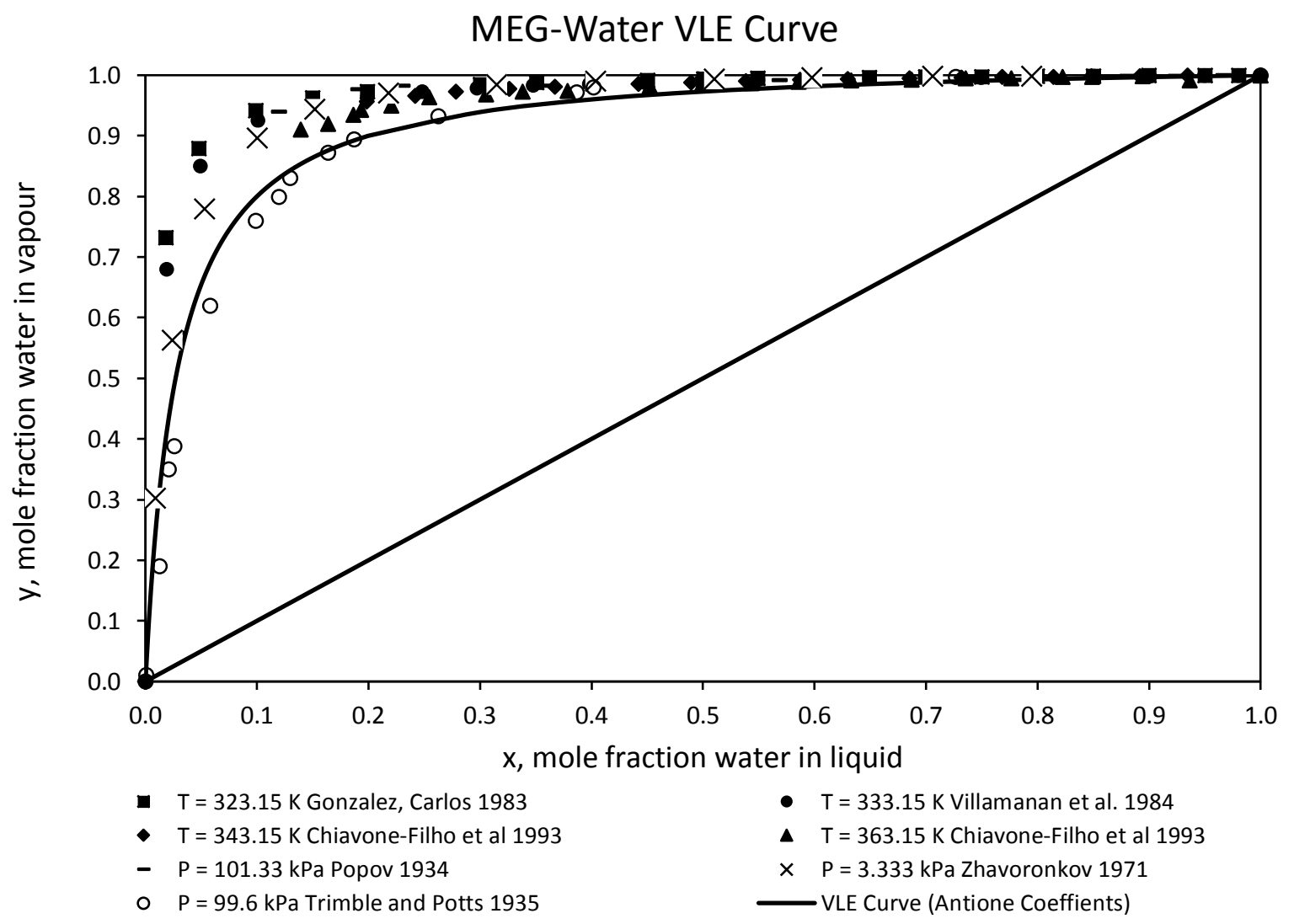

Figure 7: Literature MEG-Water VLE Data

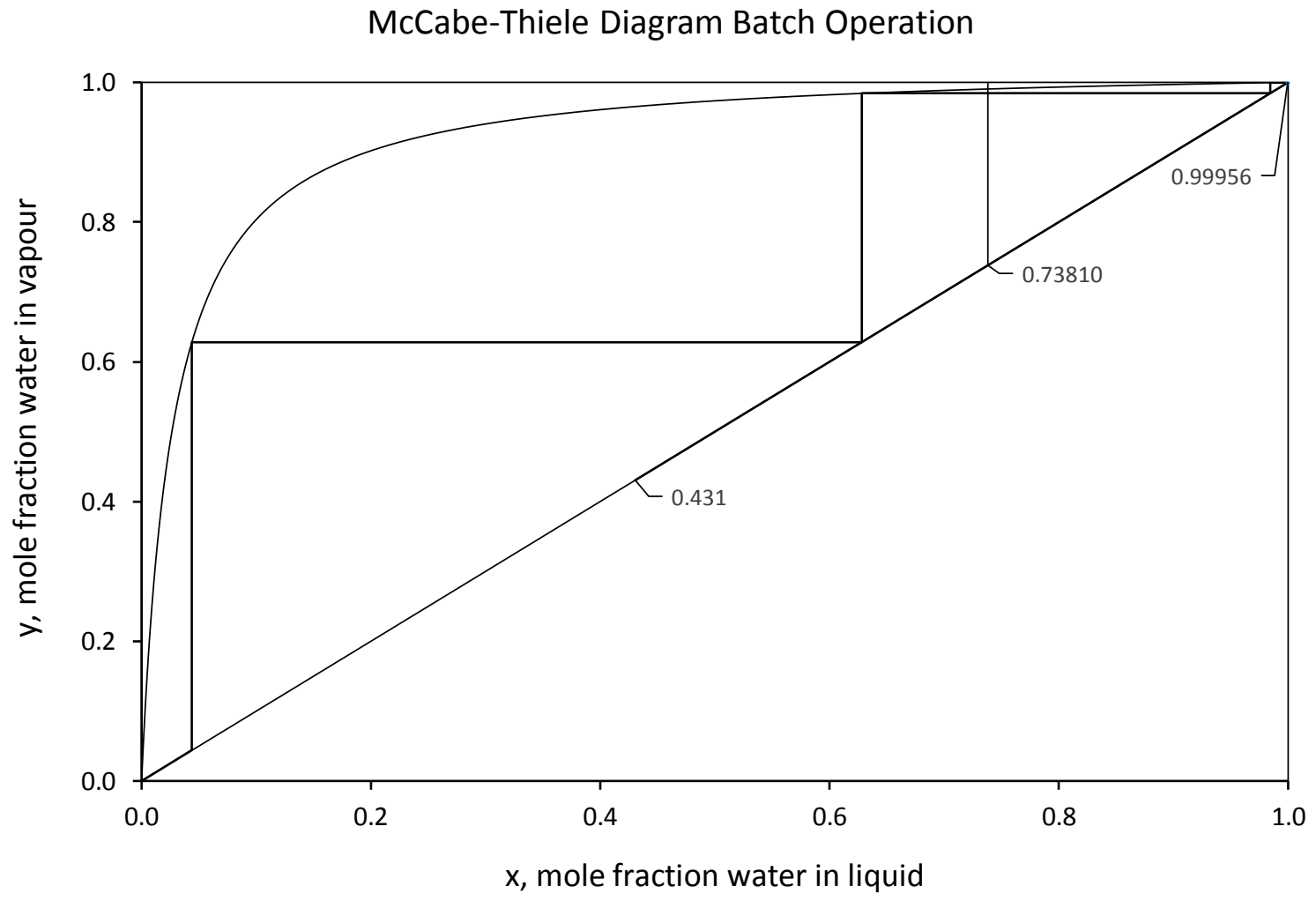

Figure 8: McCabe-Thiele Diagram, Batch Trial (1) 
McCabe-Thiele Diagram Continuous Operation

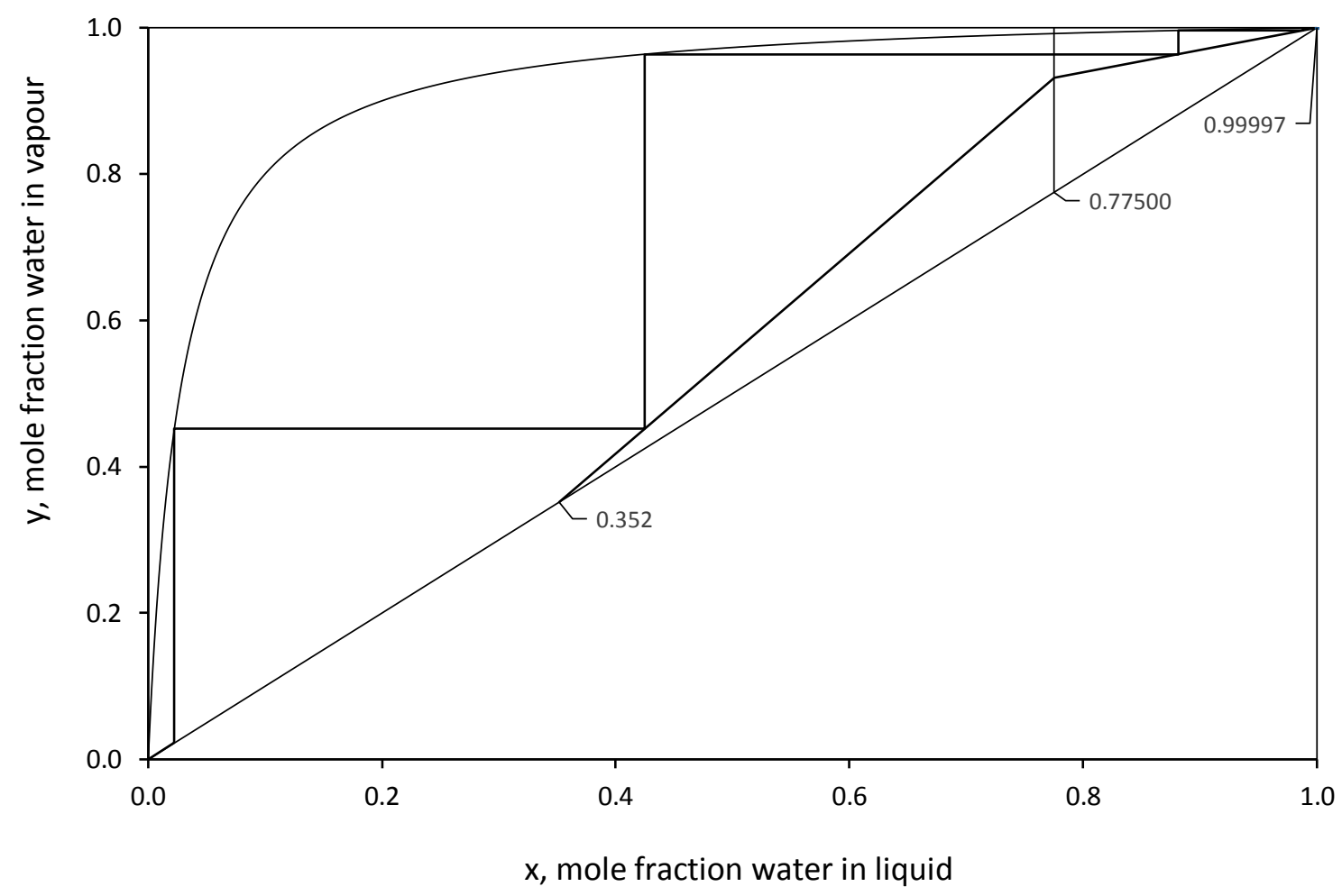

Figure 9: McCabe-Thiele Diagram, Continuous Trial (6)

McCabe-Thiele Diagram Continuous Operation with Salts

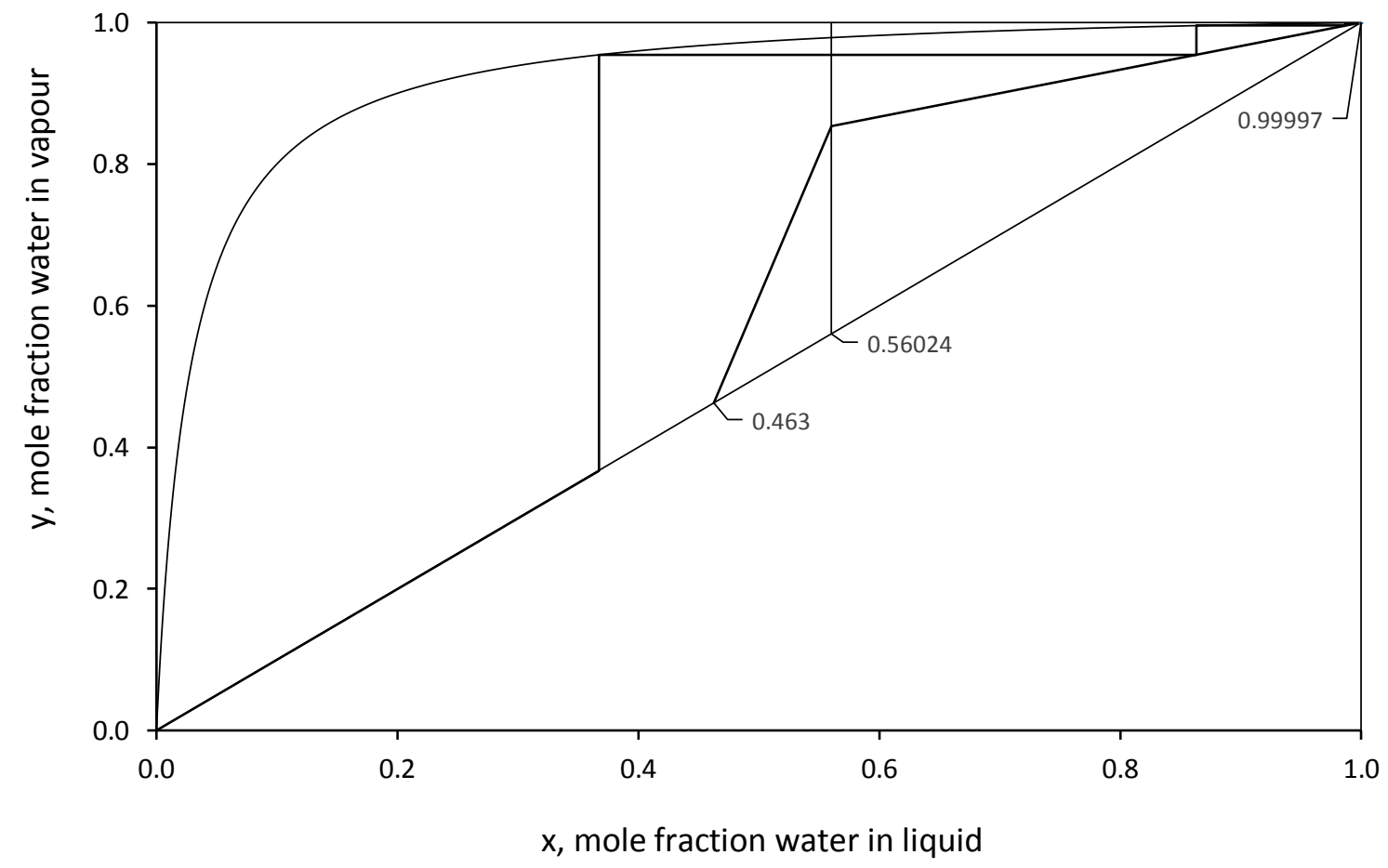

Figure 10: McCabe-Thiele Diagram, Continuous Trial (16) 


\subsection{Simulation of MEG-Water System}

In order to evaluate the experimental results of each trial, simulations were conducted to model the expected recovery of the MEG-Water distillation system. Simulation of the MEG-Water binary system was performed using the rigorous distillation column models available in Aspen HYSYS and Aspen Plus. As indicated by Table 11, separate simulations were performed utilising the HYSYS Peng-Robinson property package, the HYSYS Glycol package and the ELECNRTL package available within Aspen Plus. The Peng-Robinson Equation of State (EOS) was selected for its reliability in simulating a wide range of systems, typically comprised of non-polar light hydrocarbons. Although water and MEG are non-hydrocarbon polar components the Peng-Robinson package was considered suitable as the system to be simulated operates at atmospheric pressure, moderate temperatures and far below the critical properties of each component. Thus, the estimates of vapour properties and component volatility by the package can be considered reliable for initial simulations. The default PengRobinson fluid package available within HYSYS was utilised for simulation with no binary parameters associated with the package altered during simulation.

To further improve the capabilities of the developed model, the ELECNRTL Aspen Plus property package was also investigated for its capabilities in simulating electrolytes, such as those commonly experienced industrially during rich MEG regeneration. Initial simulations were performed to evaluate the accuracy of the base property package when simulating only Meg-Water distillation when no dissolved salts were present in order to compare it to the Peng Robinson package. In addition, upon the recommendation of the HYSYS property package selection assistant for systems containing glycols, additional simulations were performed using the available Glycol package.

The experimental operating conditions of the lab-scale MEG recovery column were used as the basis of each simulation. The reboiler operating temperature and reflux ratio of each trial were used as the rigorous columns operating specifications. The feed pressure and temperature for each trial was set at $140 \mathrm{kPa}$ and $30^{\circ} \mathrm{C}$ respectively with the condenser and reboiler operating pressure maintained at 120 and $130 \mathrm{kPa}$ respectively as per Table 3. The main assumptions made in order to develop and simulate the distillation model include:

- Stream flow rates were considered constant and the average flow rate during plant operation was used

- Reboiler temperature remained constant at the specified operating temperature through monitoring and adjustment by the PLC unit.

- Salt free trials consisted of only MEG and water

- Dissolved salt trials consisted of MEG, water and monovalent ions. The majority of divalent ions present within the rich MEG feed are removed prior to distillation during pre-treatment and the impact of remaining divalent ions as given by Table 8 are negliable when compared to the monovalent ions $\mathrm{Na}^{+}$ and $\mathrm{K}^{+}$.

- The formation and precipitation of divalent salts during distillation was not simulated due to the low concentration of divalent ions within the rich MEG feed. The formation of monovalent salts was also not considered as they are unlikely to precipitate out within the reboiler unit of a MEG regeneration column.

The results of each simulation can be found within Table 11 for both salt free and dissolve salt trials for each of the selected fluid packages and their associated average accuracy when compared to the experimental data. Additionally, Figure 11 illustrates the relationship between reboiler temperature and lean MEG purity as well as a comparison between experimental and simulated results. Only the Peng-Robinson and ELECNRTL simulation results were illustrated due to the inaccuracy of the results generated by the Glycol fluid package during simulation. The experimental trials involving dissolved salts were also included to visually express the impact of dissolved salts on the lean MEG purity. Lastly, the impact of MEG mass fraction in the feed upon the lean MEG purity was investigated for constant reboiler temperature trials as Table 12. Trials were performed using a constant reboiler temperature of $141^{\circ} \mathrm{C}$ for feed fractions ranging from 45 to $65 \%$ by weight MEG. Lean MEG purities for each trial were subsequently estimated using HYSYS and Aspen Plus with the relationship between feed fraction and lean MEG purity illustrated in Figure 12.

Through simulation it was observed that the results obtained using the Peng-Robinson property package were the most consistent with the lean MEG purities obtained through operation of the column when no salts were present. From Table 11, the Peng Robinson package was capable of simulating the lean MEG purity within on 
average $0.72 \%$ of the experimentally achieved recovery in comparison to $1.40 \%$ by the ELECNRTL package. However, the HYSYS Glycol property package was the least accurate of the tested fluid packages typically estimating a lean MEG purity significantly less than that found experimentally. In contrast, the experimentally obtained lean MEG purities for trials involving dissolved salts were significantly lower than that reported by the respective simulations. The Peng-Robinson and ELECNRTL fluid packages were only capable of simulating salt trials within $7.79 \%$ and $9.59 \%$ on average respectively, suggesting the dissolved salt content of the rich MEG has a major impact on achievable lean MEG purity during distillation.

The uncertainty associated with the reported experimental data is expressed within Figures 11, 12 and 13 as uncertainty bars. The uncertainty bars represent the combined uncertainty associated with the measurements made in terms of reboiler operating temperature and the mass fraction of MEG as reported by MEG the refractometer. The errors associated with the reboiler thermometer and MEG refractometer range from $\pm 1^{\circ} \mathrm{C}$ and $\pm 0.4 \% \mathrm{v} / \mathrm{v}$ respectively as per Section 4.0 .

\section{Table 11 - MEG-Water Simulation Results}

\begin{tabular}{|c|c|c|c|c|}
\hline \multirow{3}{*}{$\begin{array}{c}\text { Trial } \\
\text { No. }\end{array}$} & \multirow{3}{*}{ Experimental Lean MEG Purity } & \multicolumn{3}{|c|}{ Simulated Lean MEG Purity } \\
\hline & & \multicolumn{2}{|c|}{ Aspen HYSYS } & \multirow{2}{*}{$\begin{array}{l}\text { Aspen Plus } \\
\text { ELECNRTL }\end{array}$} \\
\hline & & Peng-Robinson & Glycol Package & \\
\hline \multicolumn{5}{|c|}{ Salt Free Trials } \\
\hline (3) & 0.776 & 0.7837 & 0.7131 & 0.7966 \\
\hline (4) & 0.834 & 0.8249 & 0.7647 & 0.8387 \\
\hline (5) & 0.848 & 0.8384 & 0.7821 & 0.8523 \\
\hline (6) & 0.864 & 0.8565 & 0.8056 & 0.8702 \\
\hline (7) & 0.860 & 0.8619 & 0.8128 & 0.8755 \\
\hline (8) & 0.868 & 0.8671 & 0.8197 & 0.8806 \\
\hline (9) & 0.876 & 0.8815 & 0.8388 & 0.8945 \\
\hline \multicolumn{2}{|c|}{ Average Percentage Experimental Deviation } & $0.72 \%$ & $6.61 \%$ & $1.40 \%$ \\
\hline \multicolumn{5}{|c|}{ Dissolved Salt Trials } \\
\hline$(10)$ & 0.740 & 0.7836 & - & 0.7966 \\
\hline$(11)$ & 0.720 & 0.7836 & - & 0.7966 \\
\hline$(12)$ & 0.750 & 0.8246 & - & 0.8387 \\
\hline (13) & 0.780 & 0.8247 & - & 0.8387 \\
\hline (14) & 0.750 & 0.8246 & - & 0.8387 \\
\hline$(15)$ & 0.770 & 0.8247 & - & 0.8387 \\
\hline$(16)$ & 0.800 & 0.8565 & - & 0.8702 \\
\hline \multicolumn{2}{|c|}{ Average Percentage Experimental Deviation } & $7.79 \%$ & - & $9.59 \%$ \\
\hline
\end{tabular}

\section{Table 12 - MEG Purity vs. MEG Feed Mass Fraction}

\begin{tabular}{ccccc}
$\begin{array}{c}\text { Reboiler } \\
\text { Temperature }\left({ }^{\circ} \mathrm{C}\right)\end{array}$ & MEG Feed Fraction & Lean MEG Purity & $\begin{array}{c}\text { Peng Robinson } \\
\text { Estimated Purity }\end{array}$ & $\begin{array}{c}\text { ELECNRTL Estimated } \\
\text { Purity }\end{array}$ \\
142 & 45 & 0.854 & 86.71 & 88.06 \\
141 & 50 & 0.864 & 86.2 & 87.54 \\
141 & 55 & 0.854 & 86.19 & 87.55 \\
141 & 60 & 0.86 & 86.2 & 87.57 \\
141 & 65 & 0.86 & 86.19 & 87.58 \\
\hline
\end{tabular}


Reboiler Temperature Vs. Lean MEG Purity

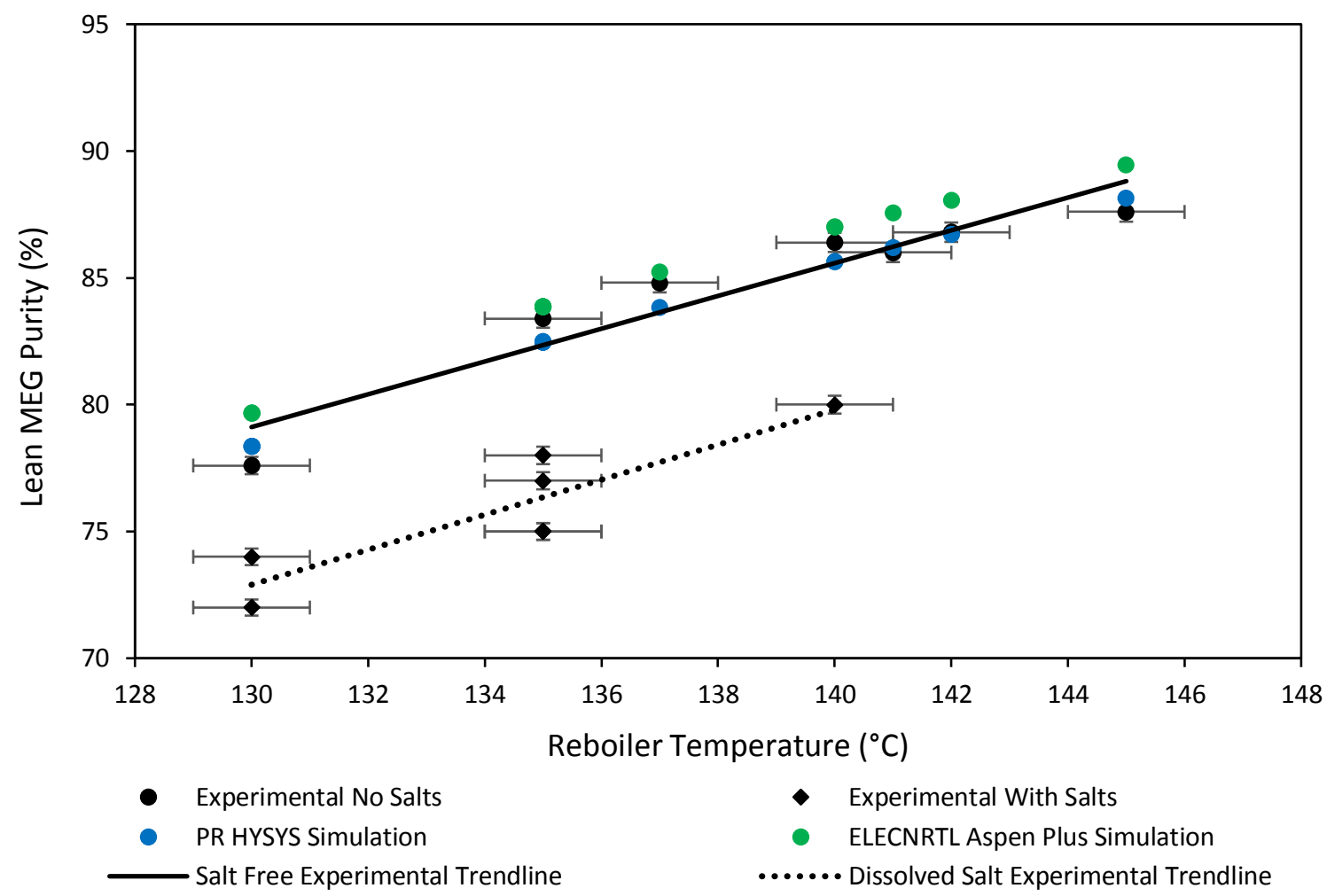

Figure 11: Reboiler Temperature vs. Lean MEG Purity (Experimental and Simulated)

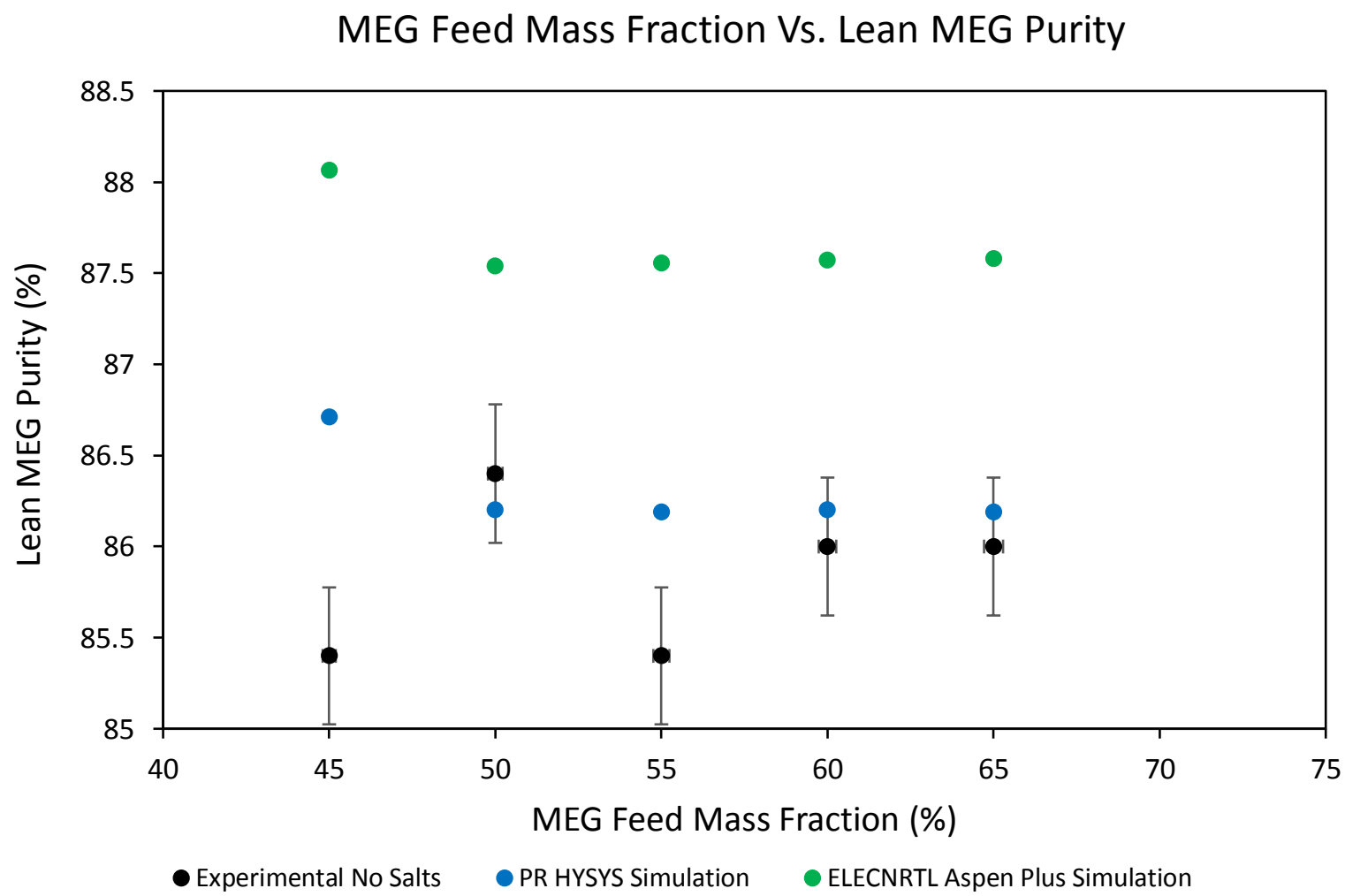

Figure 12: Feed MEG Mass Fraction vs. Lean MEG Purity (Experimental and Simulated) 
In order to improve the accuracy of the ELECNRTL fluid package for simulating salt free trials the binary parameters associated with the package were adjusted using the data regression function within Aspen Plus. Several sets of isobaric VLE data sets available within the Aspen Plus database were used to regress the MEG and water NRTL binary parameters $a_{i j}, b_{i j}$ and $c_{i j}$ to find the best fit with respect to the experimental data. The ELECNRTL property package is consistent with the NRTL-Redlich-Kwong property method utilising the NRTL model given by Equation (21) with the temperature dependant parameter, $\tau_{i j}$, given by Equation (23). Additional trials not listed in Table 6, were used to allow a more accurate fitting of the binary parameters for the ELECNRTL property package. It was found that the VLE data reported by Kamihama et al. (2012) provide the best fit for the experimental achieved lean MEG purities within this study.

The new NRTL binary parameters were regressed using the VLE data by Kamihama et al. (2012) as a basis and then further modified to generate the binary components found in Table 13 where components $i$ and $j$ are MEG and water respectively. Simulations involving the ELECNRTL package for salt free trials were then re-performed using the newly modified ELECNRTL package with results shown in Table 14 and graphically illustrated by Figure 13. It was observed that the modified binary parameters allowed a much more accurate estimation on average of the lean MEG purity consistent with experimentally achieved results. Attempts were also made to regress more accurate binary parameters for the Peng Robinson property package within Aspen Plus but it was determined that the default Peng Robinson fluid package within Aspen HYSYS was the most accurate. The VLE curve for the MEG-Water system derived from the modified NRTL binary parameters and the default Peng Robinson EOS available within HYSYS is given by Figure 14. The VLE data was generated using the binary analysis capabilities of Aspen Plus and the 'Equilibrium Unit Operation' model within HYSYS at a constant pressure of 130 $\mathrm{kPa}$ as per the operating pressure of the reboiler.

Where:

$$
\ln \gamma_{i}=\frac{\sum_{j} x_{j} \tau_{i j} G_{j i}}{\sum_{k} x_{k} G_{k i}}+\sum_{j} \frac{x_{j} G_{i j}}{\sum_{k} x_{k} G_{k j}}\left(\tau_{i j}-\frac{\sum_{k} x_{k} \tau_{k j} G_{k j}}{\sum_{k} x_{k} G_{k j}}\right)
$$

$$
\begin{gathered}
G_{i j}=\exp \left(-\alpha_{i j} \tau_{i j}\right) \\
\tau_{i j}=a_{i j}+\frac{b_{i j}}{T}+c_{i j} \ln T
\end{gathered}
$$

\begin{tabular}{ccccc}
\hline A $i j$ & $\mathrm{~A} j i$ & $\mathrm{~B} i j$ & $\mathrm{~B} j i$ & $\mathrm{C} i j$ \\
-1.77 & 1.9479 & 912.662 & -1024.5 & 0.3 \\
\hline Table 14 - Salt Free ELECNRTL & MEG-Water Simulation Results with Adjusted Binary Parameters
\end{tabular}

Trial No.

Reboiler Temp

Experimental

Original ELECNRTL

Modified ELECNRTL

(3)

(4)

(5)

(5)

(7)

(8)

(9)

$\begin{array}{ll}130 & 0.776 \\ 135 & 0.834 \\ 137 & 0.848 \\ 137 & 0.840 \\ 137 & 0.844 \\ 140 & 0.864 \\ 141 & 0.854 \\ 141 & 0.860 \\ 142 & 0.868 \\ 144 & 0.880 \\ 145 & 0.876\end{array}$

0.797
0.839
0.852
0.852
0.852
0.870
0.876
0.876
0.881
0.890
0.895
$1.45 \%$

0.782

0.825

0.839

0.839

0.839

0.858

0.864

0.864

0.869

0.879

0.884

$1.45 \%$

$0.63 \%$ 


\section{ELEC NRTL Binary Parameter Adjustment}

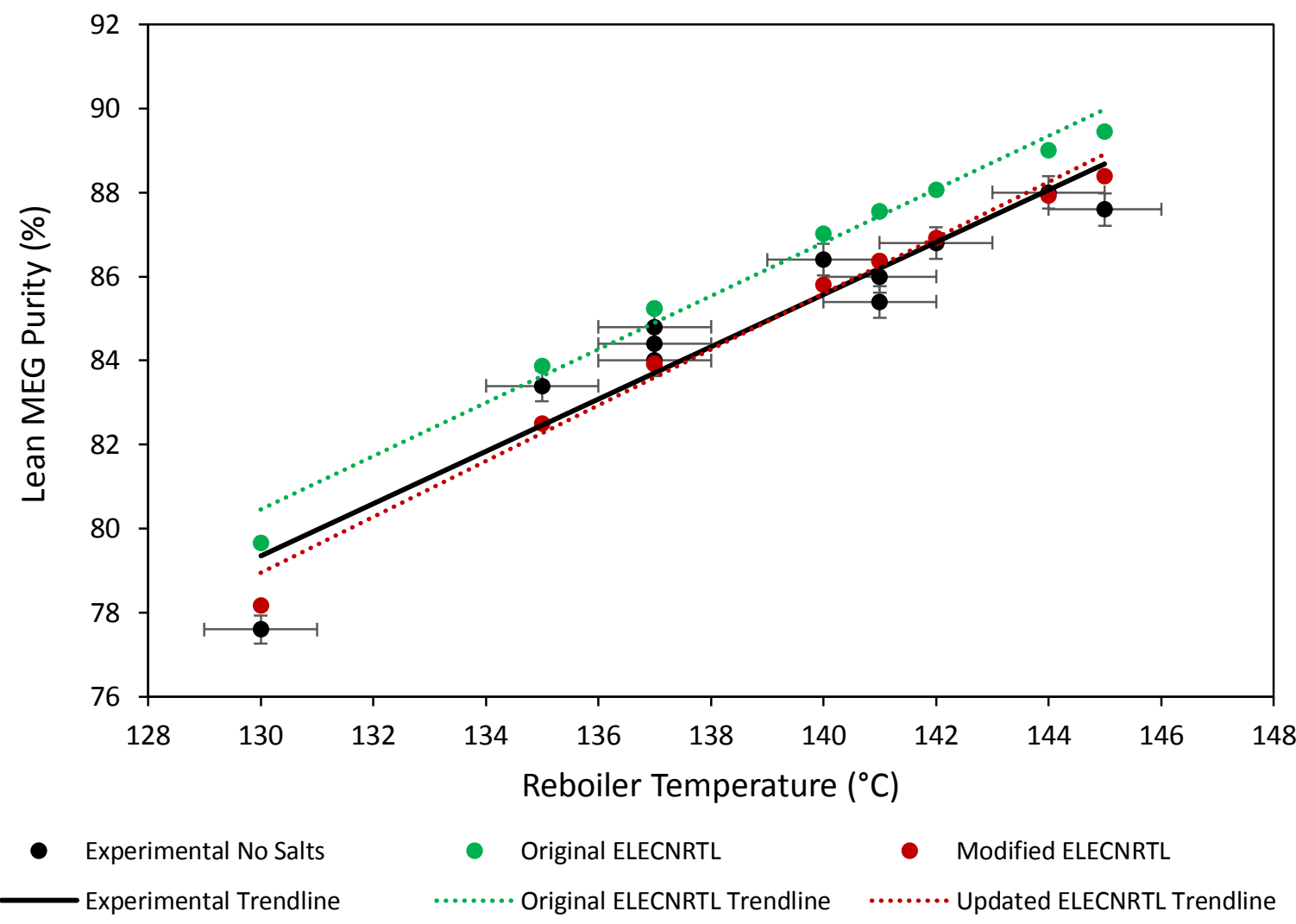

Figure 13: Modified ELECNRTL Binary Parameter Simulation Results

Simulated MEG-Water VLE Data

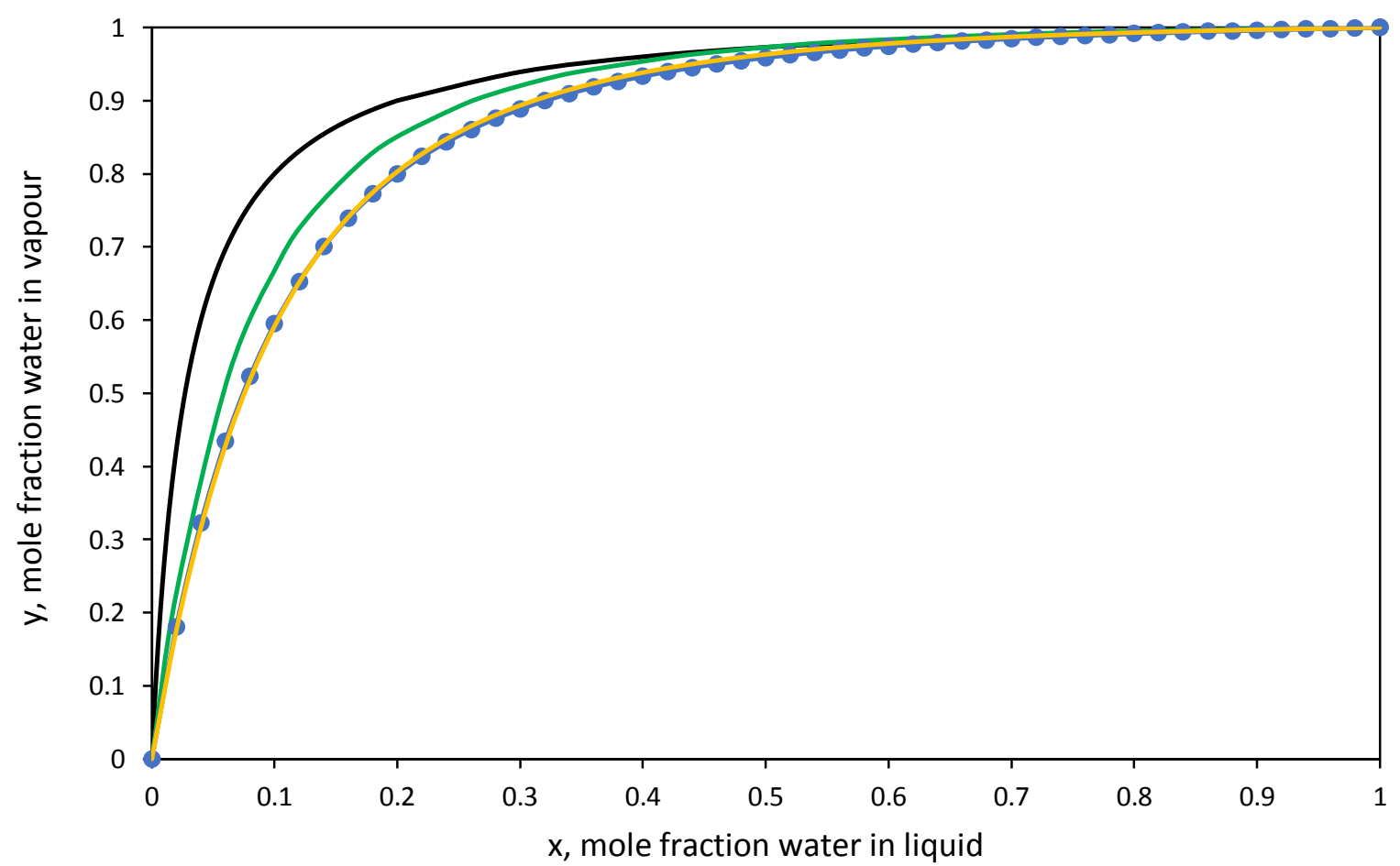

— Antione Coefficients — Kamihama et al. (2012)—Modified ELECNRTL — HYSYS Peng Robinson 


\subsection{Simulation of Dissolved Salt Impact upon Operation}

Modelling the impact of dissolved salts upon the operation of the distillation column was performed using the salt simulation capabilities of the Aspen Plus ELECNRTL model. The presence of salts within the rich MEG feed to the distillation column was modelled using the dissociation of $\mathrm{NaOH}$ and $\mathrm{KOH}$ to their respective mono-valent cations to produce the salt concentrations listed in Table 8 within the feed stream. This was achieved by calculating the amount of $\mathrm{NaOH}$ and $\mathrm{KOH}$ required using the known concentration of the respective cations, stream flow rates and dissociation reaction stoichiometric ratios. Only the impact of monovalent salt ions, $\mathrm{Na}^{+}$ and $\mathrm{K}^{+}$were included in the analysis as the majority of divalent cations would be removed in the pre-treatment stage prior to the distillation column in industrial regeneration systems. Thus, due to their low concentration their impact can be considered minimal compared to the much greater presence of monovalent cations within the rich MEG. Furthermore, the formation and precipitation of salts was not modelled as the high solubility of monovalent cations ensures they remain dissolved during distillation to be later removed downstream within the reclaimer unit (Latta et al. 2016).

The results of dissolved salt simulation are summarised within Table 15 of which compares simulation results produced by both the original and modified ELECNRTL fluid packages when dissolved salts are included and compared graphical in Figure 15. it can be seen that the ELECNRTL package modified with the reported binary parameters allowed a more accurate estimation of the lean MEG purity in comparison to the original ELECNRTL fluid package when salts where excluded and included. Overall, the Modified ELECNRTL fluid package when salts where incorporated was able to simulate the experimentally determined lean MEG purity within $1.61 \%$ on average compared to $9.59 \%$ of the simulations reported in Table 11 . From this it can be determined that the presence of monovalent cations and to an extent divalent cations within the rich MEG feed to MEG regeneration column can have a significant impact on the achievable lean MEG purity and can be modelled with relative accuracy.

Table 15 - MEG-Water Simulation Results

\begin{tabular}{|c|c|c|c|c|}
\hline $\begin{array}{c}\text { Trial } \\
\text { No. }\end{array}$ & $\begin{array}{c}\text { Experimental Lean } \\
\text { MEG Purity }\end{array}$ & $\begin{array}{c}\text { Original ELECNRTL } \\
\text { (No Salts) }\end{array}$ & $\begin{array}{c}\text { Original ELECNRTL } \\
\text { (With Salts) }\end{array}$ & $\begin{array}{c}\text { Modified ELECNRTL } \\
\text { (With Salts) }\end{array}$ \\
\hline$(10)$ & 0.74 & 0.7966 & 0.725 & 0.715 \\
\hline$(11)$ & 0.72 & 0.7966 & 0.724 & 0.714 \\
\hline$(12)$ & 0.75 & 0.8387 & 0.777 & 0.765 \\
\hline$(13)$ & 0.78 & 0.8387 & 0.774 & 0.763 \\
\hline$(14)$ & 0.75 & 0.8387 & 0.774 & 0.763 \\
\hline$(15)$ & 0.77 & 0.8387 & 0.782 & 0.771 \\
\hline$(16)$ & 0.80 & 0.8702 & 0.819 & 0.808 \\
\hline \multicolumn{2}{|l|}{ Average Percentage Experimental } \\
Deviation
\end{tabular}


ELECNRTL vs. Experimental Salt Trials

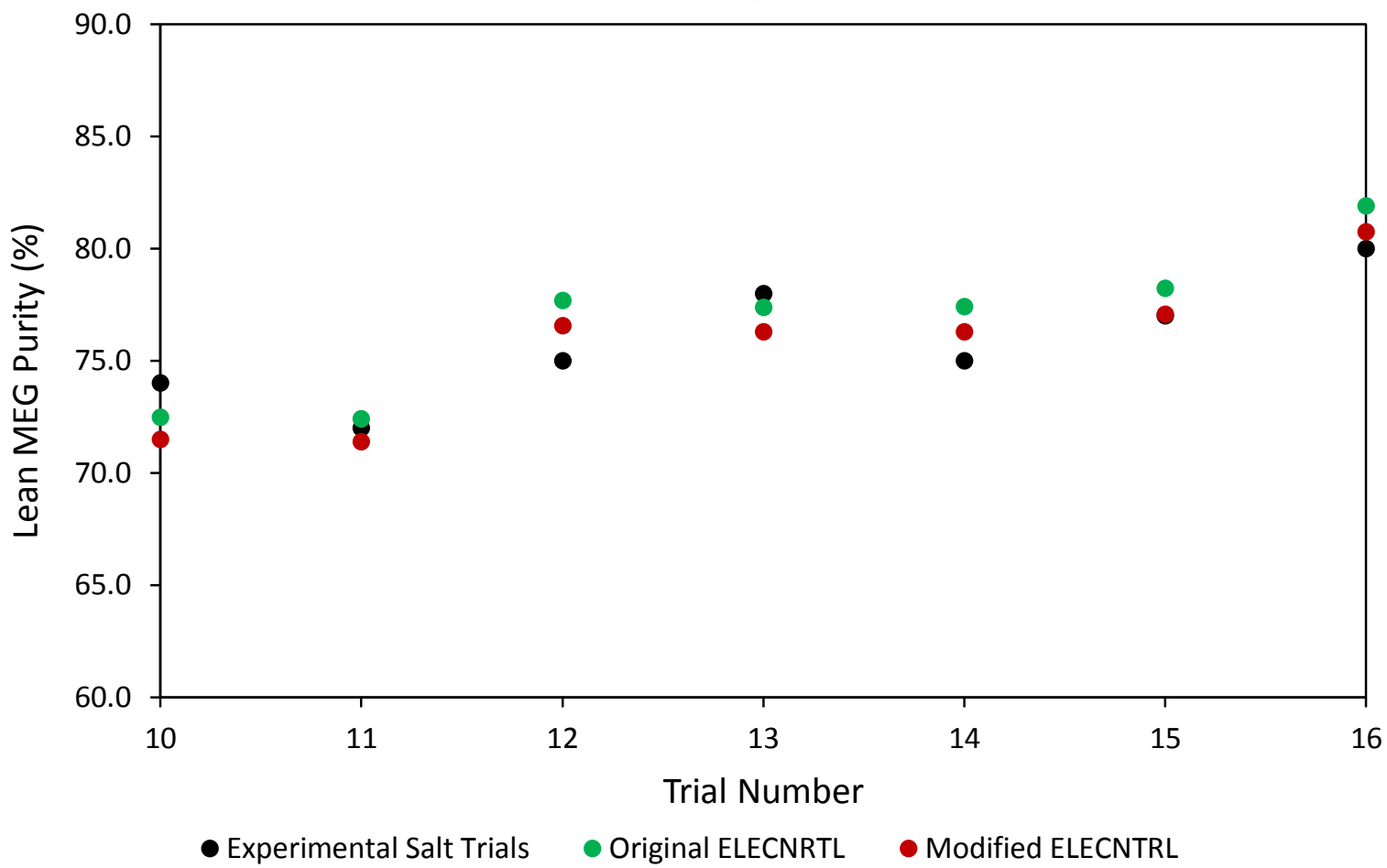

Figure 15: ELECNRTL Simulated Dissolved Salt Lean MEG Purities 


\subsection{Discussion}

The design and construction of the MEG distillation column utilised in this study was performed to investigate the recovery of MEG within a pilot scale packed distillation column. Through the experimental trials conducted, the validity of the design for the separation of water from MEG was confirmed. Operation of the distillation column was successfully performed under varying feed and reboiler conditions with lean MEG purities above $80 \%$ by mass achieved. Furthermore, operation of the column was successfully tested upon the introduction of dissolved salts into the rich MEG feed.

One of the primary aspects of this study was to evaluate the design of the MEG distillation column and assess its performance under varying operation conditions. The column was operated using both batch and continuous operation utilising a wide range of both MEG feed mass fractions and reboiler operating temperatures and the impact on lean MEG purity investigated. It was found when operating under batch conditions the number of theoretical stages required to achieve separation was three, of which corresponds to the minimum number of stages required under total reflux. However, when operating at a finite reflux typically between 0.4-0.6 by weight under continuous operation, the actual number of theoretical stages was estimated to be six. It can be observed through Table 6 that under both batch and continuous operation when no salts are present within the rich MEG feed, a lean MEG purity above $80 \%$ can be achieved when operating the reboiler above $135^{\circ} \mathrm{C}$. Although as expected, under batch operation the achieved MEG concentration within the distillate water product was significantly higher than under continuous operation.

Estimation of the number of transfer units for each continuous trial as per Table 10, provides a measure of the performance of the column under varying operating conditions. For each trial the number of transfer units indicates the difficulty of the separation and was estimated via numerical integration of Equation (4) based upon vapour phase compositions calculated along the stripping and rectifying operating lines and at equilibrium by the VLE curve. The concept of transfer units is considered to be the most accurate way of estimating a columns performance and required height of packing in comparison to other methods including HETP. However, a major problem faced in analysing the experimental results reported using transfer units was the steep nature of the NTU curve as a result of the low mass fraction of MEG in the distillate product (100ppm). The NTU curve for Continuous Trial (6) is displayed in Figure 16 exhibiting the steep NTU curve as the vapour composition reaches one. Due to the steep curve produced, estimation of the number of transfer units by calculation of the area under the curve by both graphical and numerical integration was highly dependent on the step size chosen. As such it was difficult to estimate the number of transfer units accurately and was thus considered a poor representation of the columns performance in comparison to the number of theoretical stages estimated by the FUG shortcut method.

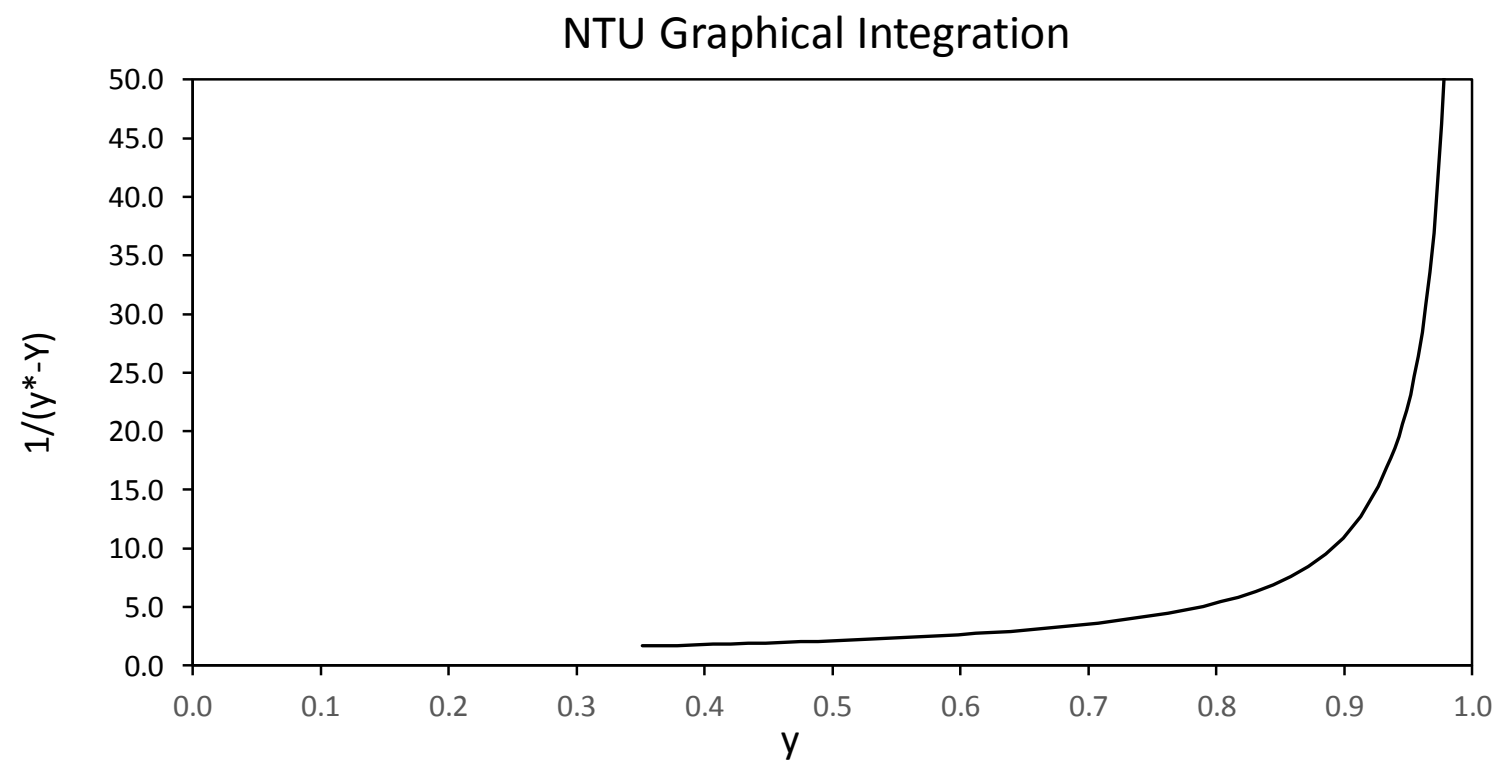

Figure 16: Continuous Trial (6) NTU Graphical Integration 
Additional calculations were then performed in order to estimate the overall height of the gas phase transfer unit to assess the effectiveness of the packing in separating MEG from water. It was found for continuous trials with no dissolved salts that the average HTU was approximately 0.306 metres, however, when dissolved salts were introduced the HTU decreased to between 0.229-0.217 metres suggesting an increase in packing performance. This directly contradicts what was believed to occur upon the introduction of salts into the rich MEG feed, where the presence of salts was thought to decrease the packings performance. However, through calculation it was observed that the effect of dissolved salts, primarily through increased density and viscosity of the liquid within the reboiler had only a minor impact upon the estimated HTU. Instead, the HTU was primarily influenced by the fraction of MEG within the feed and the relative difference between MEG feed fraction and the final fraction of MEG within the lean MEG product. A lower mass fraction of water within the feed directly resulted in a decreased amount of water boiled within the reboiler and returned to the column as boil up. This was compounded when conducting salt trials due to the lower lean MEG product purity achieved as per Table 6. This further reduced the boil up returned to the column as more water was retained within the bottoms product. The combination of these factors ultimately reduced the vapour and liquid throughput of the column and by extension the vapour and liquid superficial velocities utilised in Equations (6) and (7) reducing the estimated HTU. Overall, it can be assumed that the column was not operating at maximum capacity and a lower rate of mass transfer between the liquid and vapour phase occurred.

The HTU for each trial was then used as a basis to estimate the HETP by application of Equation (9). It was observed for salt free trials the packing achieved a HETP of approximately 0.33-0.35 metres, slightly lower than that estimated using the known height of packing and estimated number of theoretical plates for each trial by Equation (8). From the estimated HETPs the expected height of packing can be calculated, and was estimated at approximately 1.7 metres. This is slightly lower than the height of packing utilised within the column but with additional safety margins and rounding up to the next standard height of a packing section a height of 1.8 metres $(900 \mathrm{~mm} \times 2)$ is realistic. Again, it was observed that for trials involving dissolved salts within the rich MEG feed the HETP decreased significantly suggesting an increase in column performance when salts are present. However similar to the HTUs estimated, the reduced HETP can be attributed to the reduced liquid and vapour flow rates within the column. Furthermore, estimation of the HTU and HETP for batch trials was not conducted as the column will primarily be operated under continuous conditions.

To further evaluate the operation of the pilot MEG distillation column, simulations were performed using Aspen HYSYS and Plus to investigate how closely simulations conformed to the experimentally determined lean MEG purities. Initial simulations performed using the Peng Robinson fluid package available within Aspen HYSYS was found to provide an accurate estimation of lean MEG purity in comparison to the respective salt free operational trials. As can be seen visually through Figure 11, the lean MEG purities estimated through HYSYS simulation closely matched those obtained through experimental means with the estimated trend lines of both the salt free experiments and simulated data points in close agreement. Furthermore, as can be expected, a clear relationship between the operating temperature of the reboiler and the purity of the lean MEG is evident. However, no clear relationship between the fraction of MEG in the feed and experimental lean MEG purities was observed in Figure 12 with Aspen HYSYS and Plus both suggesting the lean MEG purity is independent of the feed fraction. This can be attributed to the nature of MEG distillation where there is a large difference in volatility between MEG and water resulting in an almost $100 \%$ pure water distillate. As such, although the salt trials outlined in Table 11 were conducted with higher MEG feed fractions, the difference in the lean MEG purities observed in comparison to the salt free trials can be attributed to the presence of dissolved salts.

Likewise, the default ELECNRTL fluid package within Aspen Plus was found to be able to predict the experimentally lean MEG with reasonable but lower accuracy than the HYSYS Peng Robinson EOS. However, with adjustment of the property package's binary parameters, the accuracy of the ELECNRTL package for simulating the MEG-Water system was able to be significantly improved surpassing that of the HYSYS Peng Robinson EOS. Furthermore, the ELECNRTL package includes the capability of simulating the impact of electrolytes such as dissolved salts that are common in industrial MEG processing after the production of formation water during hydrocarbon production. The NRTL binary parameters found to be suitable for simulating salt free MEG-Water distillation are reported in Table 13. 
VLE data for the simulated MEG-Water system was also generated using the capabilities of Aspen HYSYS and Plus using the HYSYS Peng Robinson and modified ELECNRTL fluid packages respectively. Figure 14 graphically compares the MEG-Water VLE data of that calculated through Antione coefficients as per Figure 7, simulation by Aspen HYSYS and Plus and the literature VLE data reported by Kamihama et al. (2012) that was used as the basis for NRTL binary parameter regression. It is clear that the VLE data estimated by simulation within this study deviates significantly from that reported in literature and graphed within Figure 7. This can be attributed to the different test conditions at which the literature MEG-Water binary VLE data was reported at. These test conditions are not representative of the typical operating conditions at which an industrial MEG distillation column typically operates, namely atmospheric pressure and $120-160^{\circ} \mathrm{C}$ Psarrou et al (2011). The VLE data generated within this study was matched to experimental data of a real MEG pilot plant, operating at typical industry conditions and thus can be considered more accurate for future design of such systems compared to previous literature data.

The primary outcome observed during analysis of the experimental results by simulation was the impact of dissolved salts within the rich MEG feed upon the purity of the final lean MEG product. The purity of lean MEG in trials including dissolved salts deviated significantly from both corresponding salt free trials with similar reboiler operating temperatures and expected results derived from initial simulations when salts were unaccounted for. This phenomenon is observed through the experimentally obtained lean MEG purities reported in Table 7 and Figure 11 where the purity of salt trials is observed to be notably less than the produced trend lines for both experimental and simulated results. Furthermore, the HETP estimated for trials involving dissolved salts were also noticeably less indicating a poorer separation performance of the column. However, the impact of dissolved salts upon the achieved lean MEG purity during operation was able to be predicted within an average deviation of $1.61 \%$ from the experimental results as indicated by Table 15 . The introduction of $\mathrm{Na}^{+}$and $\mathrm{K}^{+}$ions into the simulated rich MEG feed based on experimental concentrations showed noticeable impact upon the lean MEG purity reported during simulation. On average, the inclusion of monovalent cations within the simulation reduced the achieved lean MEG purity by $7.65 \%$ for trials with total monovalent concentrations between 10000-12000 ppm.

The impact of the dissolved salts analysed within this work upon the operation of both the pilot MEG column and simulation models can be attributed to the boiling-point elevation of the MEG-Water solution due to the presence of the mono-valent cations, $\mathrm{Na}^{+}$and $\mathrm{K}^{+}$. The presence of such non-volatile solute within the solution directly reduces the overall vapour pressure of the MEG-Water solution thus requiring a greater reboiler operating temperature for boiling to occur. The effects of various salts on the boiling point of aqueous solutions has been documented by various authors including Bialik, Sedin, and Theliander (2008) and Meranda and Furter (1977). Furthermore, the presence of dissolved salts within the MEG-Water solution can have pronounced effects upon the VLE curve of the system. The impact of dissolve salts upon the VLE curve of various binary systems and methods to predict such impacts have been outlined by Aznar and Telles (2001), Chou and Tanioka (1999) and Kumar (1993).

The impact of salts on the MEG distillation process was primarily thought to occur through oversaturation of soluble salts, primarily divalent salts including $\mathrm{CaCO}_{3}$ and $\mathrm{FeCO}_{3}$ leading to salt deposition within processing equipment (Latta, Seiersten, and Bufton 2013, Bikkina et al. 2012). The process of salt precipitation in industrial regeneration of MEG is a major contributor to poor separation performance due to fouling and the accumulation of suspended solids within the reboiler unit causing reduced heat transfer efficiency. However, the presence of dissolved mono-valent salt cations within the rich MEG was also found to have significant impact on the achievable lean MEG purity during both experimental operation of the pilot MEG plant and simulated models. To accommodate the impact of dissolved salts a higher reboiler temperature would be required to maintain a constant boil up rate and lean MEG purity compared to salt free operation. However, operating the reboiler at too high of a temperature can lead to thermal degradation of the MEG as per the research performed by AlHarooni et al. (2015). Alternatively, a greater lean MEG purity can be achieved by the reduction of reboiler operating pressure but is generally avoided due to increased operating costs associated with vacuum operation. In addition, due to the inverse soluble nature of some salts including $\mathrm{CaCO}_{3}$ one of the primary salt precipitants experienced in MEG processing, higher operating temperatures may directly lead to increased salt precipitation and reboiler fouling, further reducing separation efficiency. 


\subsection{Conclusions}

The distillation column utilised within this study was designed for the separation of water from MEG when dissolved salts common in MEG systems are present. The primary aim of the initial experimental trials conducted was to verify the design of the column and to assess its performance in recovering MEG for water. It was estimated through the experimental data obtained through operation of the column that it consists of six equilibrium stages under continuous operation. Under total reflux the minimum number of equilibrium corresponds to two. Further analysis of the column through the concept of HETP evaluated the columns packing as having a HETP of approximately 0.34 metres. Through the estimated HETP in conjunction with the estimated number of theoretical stages for each trial, an estimated height of packing required to achieve separation was found to be approximately 1.7 metres. This corresponds closely with the 1.8 metres of packing utilised within the column thus verifying its design. Secondary estimation of the required packing height was also be made through the estimated HTU and NTUs for each trial, through this method the packing was estimated to be roughly 1.9-2.1 metres. However due to the inaccuracies in estimating the NTU discussed, this estimation is less reliable than that made using the HETP.

The secondary objective of this study was to investigate the impact of dissolved salts upon the recovery of MEG and upon the operational performance of the column. Estimation of the HTU and HETP of the packing for both salt and salt free trials were inconclusive in assessing the columns performance. It was observed that the presence of salts had a significant impact on the perceived performance of the column through the estimated HTUs and HETPs. However, the mass fraction of MEG in the feed and relative difference between feed and lean MEG mass fraction was found to be the underlying factor. Overall the presence of dissolved salts in the rich MEG feed primarily influenced the lean MEG purity that could be achieved during operation. It was observed that for salt trials, the experimentally achieved lean MEG purity was approximately $7.2 \%$ less than corresponding salt free trials at equal reboiler operating temperatures.

The conclusions drawn from experimental data were then further investigated through the development of distillation models using Aspen HYSYS and Plus. Of the models developed, the Peng Robinson EOS in HYSYS and the ELECNRTL package with modified binary parameters were found to generate product MEG purities in close agreement with experimental trials when no dissolved salts were present. However, upon the introduction of salts into the feed, the experimental lean MEG purities deviated significantly from the trend lines developed from simulated results for both fluid packages. It was concluded that the impact of dissolved salts upon the MEG distillation process occurred due to an increase in solution boiling point and the resulting impact on the MEGWater systems VLE. The impact of dissolved salts within the rich MEG feed was able to be predicted with an average deviation of $1.61 \%$ from experimental trials using the Aspen Plus ELECNRTL electrolyte simulation capabilities by the inclusion of monovalent cations. Overall, it was established that the impact of dissolved salts is not only limited to the effects of salt precipitation and accumulation within the reboiler unit of a distillation column but also through its impact on the VLE of the system. Therefore, the unexpected presence of dissolved salts within the rich MEG feed stream may require greater reboiler temperature to maintain a constant boil up rate potentially leading to unwanted thermal degradation of the MEG. 


\subsection{Nomenclature}

\begin{tabular}{|c|c|}
\hline$a, b, c$ & NRTL Binary parameters \\
\hline $\mathrm{a}_{\mathrm{e}}$ & Effective interfacial area of packing, $1 / \mathrm{m}$ \\
\hline$a_{p}$ & Packing specific surface area, $1 / \mathrm{m}$ \\
\hline$d_{\text {eq }}$ & Equivalent diameter of flow channel, $m$ \\
\hline $\mathrm{D}_{\mathrm{L}}$ & Liquid diffusivity, $\mathrm{m}^{2} / \mathrm{s}$ \\
\hline $\mathrm{D}_{\mathrm{G}}$ & Gas diffusivity, $\mathrm{m}^{2} / \mathrm{s}$ \\
\hline $\mathrm{g}$ & Gravitational constant, $m / s^{2}$ \\
\hline $\mathrm{G}$ & Binary constant of the NRTL equation \\
\hline $\mathrm{G}_{\mathrm{m}}$ & Gas flowrate within the column, kgmole/hr \\
\hline HETP & Height Equivalent to a Theoretical Plate, $\mathrm{m}$ \\
\hline $\mathrm{H}_{\mathrm{G}}$ & Height of gas phase transfer unit, m \\
\hline $\mathrm{H}_{\mathrm{L}}$ & Height of liquid phase transfer unit, m \\
\hline $\mathrm{H}_{\mathrm{OG}}$ & Overall height of transfer unit in gas phase, $m$ \\
\hline HTU & Height of mass-transfer unit, $\mathrm{m}$ \\
\hline $\mathrm{k}_{\mathrm{G}}$ & Gas-side mass-transfer coefficient, $\mathrm{m} / \mathrm{s}$ \\
\hline $\mathrm{k}_{\mathrm{L}}$ & Liquid-side mass-transfer coefficient, $\mathrm{m} / \mathrm{s}$ \\
\hline $\mathrm{L}_{\mathrm{m}}$ & Liquid flow rate within column, kgmole/hr \\
\hline $\mathrm{m}$ & Average slope of the VLE curve \\
\hline M & Molecular weight, g/gmole \\
\hline $\mathrm{N}$ & Number of theoretical stages \\
\hline $\mathrm{N}_{\min }$ & Minimum number of theoretical stages \\
\hline NTU & Number of transfer units \\
\hline $\mathrm{P}$ & Operating pressure, $\mathrm{kPa}$ \\
\hline $\mathrm{R}_{\min }$ & Minimum reflux ratio \\
\hline $\mathrm{s}$ & Corrugation side length, $m$ \\
\hline $\mathrm{T}$ & Temperature ${ }^{\circ} \mathrm{K}$ \\
\hline $\mathrm{u}$ & Superficial fluid velocity, $\mathrm{m} / \mathrm{s}$ \\
\hline $\mathrm{V}$ & Molar volume at normal boiling point \\
\hline $\mathrm{x}$ & Mole fraction of component in liquid phase \\
\hline$x_{i j}$ & Local molar fraction of compound $i$ around the central molecule $j$ \\
\hline $\mathrm{x}_{\mathrm{A}}, \mathrm{x}_{\mathrm{B}}$ & Mole fraction of the more volatile and less volatile component respectively \\
\hline $\mathrm{y}$ & Mole fraction of component in vapour phase \\
\hline $\mathrm{y}^{*}$ & Equilibrium vapour phase composition \\
\hline \multirow[t]{2}{*}{$\mathrm{Z}$} & Height of packing \\
\hline & Greek Letters \\
\hline$\alpha$ & $\begin{array}{l}\text { Relative volatility } \\
\text { Corrugation inclination angle, }{ }^{\circ} \mathrm{deg}\end{array}$ \\
\hline$\alpha_{i j}$ & Non randomness parameter of the NRTL equation \\
\hline$\Gamma$ & Liquid flow rate based on perimeter, $\mathrm{kg} / \mathrm{m} . \mathrm{s}$ \\
\hline$\epsilon$ & Packing void fraction \\
\hline$\varepsilon / \mathrm{k}_{\mathrm{B}}\left({ }^{\circ} \mathrm{K}\right)$ & Lennard-Jones potential parameters \\
\hline$\lambda$ & $\begin{array}{l}\text { Ratio of gas to liquid molar flow rates } \\
\text { Stripping factor }\end{array}$ \\
\hline$\mu$ & Viscosity of vapour or liquid kg/m.s \\
\hline$v$ & Kinematic viscosity of vapour of liquid $\mathrm{m}^{2} / \mathrm{s}$ \\
\hline$\rho$ & Density of vapour or liquid, $\mathrm{kg} / \mathrm{m}^{3}$ \\
\hline$\sigma$ & $\begin{array}{l}\text { Surface tension of fluid, } \mathrm{N} / \mathrm{m} \\
\text { collision diameter of particle }(\AA)\end{array}$ \\
\hline$\tau$ & NRTL temperature dependant parameter \\
\hline$\psi$ & Molokanov variable in Equation (3) \\
\hline \multirow[t]{2}{*}{$\Omega$} & Collision integral \\
\hline & Subscripts \\
\hline 1 or 2 & Component 1 or 2 \\
\hline
\end{tabular}




$\begin{array}{ll}i j & \text { Component } i \text { or } j \\ \mathrm{~B} & \text { Bottoms stream } \\ \mathrm{D} & \text { Distillate stream } \\ \mathrm{e} & \text { Effective } \\ \mathrm{F} & \text { Feed stream } \\ \mathrm{g} & \text { Gas phase } \\ \mathrm{L} & \text { Liquid phase }\end{array}$

\subsection{References}

AlHarooni, Khalifa, Ahmed Barifcani, David Pack, Rolf Gubner, and Varun Ghodkay. 2015. "Inhibition effects of thermally degraded MEG on hydrate formation for gas systems." Journal of Petroleum Science and Engineering 135:608-617. doi: http://dx.doi.org/10.1016/j.petrol.2015.10.001.

ATAGO. Digital Hand-held "Pocket" Ethylene Glycol refractometer PAL-91S. http://www.atago.net/product/?l=en\&k=ADT59550.

Aznar, M., and A.S. Telles. 2001. "Prediction of electrolyte vapor-liquid equilibrium by UNIFAC-Dortmund." Brazilian Journal of Chemical Engineering 18:127-137.

Babu, D. R., M. Hosseinzadeh, A. Ehsaninejad, R. Babaei, M. R. Kashkooli, and H. Akbary. 2015. "Carbonates precipitation in MEG loops - A comparative study of South Pars and Bass Strait gas fields." Journal of Natural Gas Science and Engineering 27, Part 2:955-966. doi: http://dx.doi.org/10.1016/j.jngse.2015.09.035.

Ben-Amotz, Dor, and Dudley R. Herschbach. 1990. "Estimation of effective diameters for molecular fluids." The Journal of Physical Chemistry 94 (3):1038-1047. doi: 10.1021/j100366a003.

Bialik, Marta, Peter Sedin, and Hans Theliander. 2008. "Boiling Point Rise Calculations in Sodium Salt Solutions." Industrial \& Engineering Chemistry Research 47 (4):1283-1287. doi: 10.1021/ie070564c.

Bikkina, Chaitanya, Narayanan Radhakrishnan, Sumit Jaiswal, Ryan Harrington, and Mark Charlesworth. 2012. "Development of MEG Regeneration Unit Compatible Corrosion Inhibitor for Wet Gas Systems." 2012/1/1/.

Bravo, Jose L., and James R. Fair. 1990. "Distillation columns containing structured packing." Chemical Engineering Progress $86(1): 19-29$.

Bravo, Jose L., J. A. Rocha, and J. R. Fair. 1985. "MASS TRANSFER IN GAUZE PACKINGS." Hydrocarbon Processing 64 (1):9195.

Brustad, S., K. P. Løken, and J. G. Waalmann. 2005. "Hydrate Prevention using MEG instead of MeOH: Impact of experience from major Norwegian developments on technology selection for injection and recovery of MEG." 2005/1/1/.

Carroll, John J. 2003. Natural gas hydrates : a guide for engineers / John J. Carroll. Amsterdam, Boston: Gulf Professional Pub.

Chapman, Sydney. 1970. The mathematical theory of non-uniform gases /Sydney Chapman and T.G. Cowling. Edited by David Burnett and T. G. Cowling. 3rd ed / prepared in co-operation with D. Burnett.. ed. Cambridge: Cambridge : Cambridge University Press.

Chou, T. J., and A. Tanioka. 1999. "Predicting the Effect of Dissolved Salt on the Vapour-Liquid Equilibria for Alcohol-WaterSalt Systems." Chemical Engineering Research and Design 77 (4):329-334. doi: http://dx.doi.org/10.1205/026387699526269.

Coker, A. Kayode. 2010. "Chapter 14 - Packed Towers." In Ludwig's Applied Process Design for Chemical and Petrochemical Plants (Fourth Edition), 483-678. Boston: Gulf Professional Publishing.

Cussler, E. L. 1997. Diffusion : mass transfer in fluid systems / E.L. Cussler. 2nd ed.. ed. Cambridge, New York: Cambridge University Press.

Diba, K.D., M. Guglielminetti, and S. Schiavo. 2003. "Glycol reclaimer." The Offshore Mediterranean Conference and Exhibition, Ravenna.

Dong, Liu, Chen ZhenYu, and Guo XingPeng. 2008. "The effect of acetic acid and acetate on CO2 corrosion of carbon steel." Anti-Corrosion Methods and Materials 55 (3):130-134. doi: 10.1108/00035590810870437.

Dutta, Binay K. 2007. Principles of mass transfer and separation processes / Binay K. Dutta. New Delhi: New Delhi : PrenticeHall of India.

Figueiredo, Cms, A. G. Barreto, Em Flaten, R. Beck, and M. Seiersten. 2015. "Crystal growth of FeCO3 in mixed monoethylene glycol and water solvent." Cryst. Res. Technol. 50 (5):354-361. doi: 10.1002/crat.201400420.

Flaten, Ellen Marie, Xiaoguang Ma, Marion Seiersten, Charlotte Aanonsen, Ralf Beck, and Jens-Petter Andreassen. 2015. "Impact of Monoethylene Glycol and Fe2+ on Crystal Growth of CaCO3." 2015/5/12/.

Flaten, Ellen Marie, Marion Seiersten, and Jens-Petter Andreassen. 2010. "Growth of the calcium carbonate polymorph vaterite in mixtures of water and ethylene glycol at conditions of gas processing." Journal of Crystal Growth 312 (7):953-960. doi: 10.1016/j.jcrysgro.2010.01.015.

Gonzalez, J.J., M.E. Alfonso, and G. Pellegrino. 2000. "Corrosion of carbon steels in mono ethylene glycol." Corrosion 2000 NACE International.

Haghighi, Hooman, Antonin Chapoy, Rod Burgess, and Bahman Tohidi. 2009. "Experimental and thermodynamic modelling of systems containing water and ethylene glycol: Application to flow assurance and gas processing." Fluid Phase Equilibria 276 (1):24-30. doi: http://dx.doi.org/10.1016/j.fluid.2008.10.006. 
Haque, Md. Emdadul. 2012. "Ethylene Glycol Regeneration Plan: A Systematic Approach to Troubleshoot the Common Problems." Journal of Chemical Engineering 27 (1):21-26.

Ikeh, Lesor, G. C. Enyi, and G. G. Nasr. 2016. "Inhibition Performance of Mild Steel Corrosion in the Presence of Co2, HAc and MEG." 2016/5/9/.

Kaasa, Baard, Kristian Sandengen, and Terje Ostvold. 2005. "Thermodynamic Predictions of Scale Potential, pH and Gas Solubility in Glycol Containing Systems." 2005/1/1/.

Kamihama, Naoki, Hiroyuki Matsuda, Kiyofumi Kurihara, Katsumi Tochigi, and Shigeo Oba. 2012. "Isobaric Vapor-Liquid Equilibria for Ethanol + Water + Ethylene Glycol and Its Constituent Three Binary Systems." Journal of Chemical \& Engineering Data 57 (2):339-344. doi: 10.1021/je2008704.

Kister, Henry Z. 1992. Distillation design / Henry Z. Kister. New York: New York : McGraw-Hill.

Kumar, Anil. 1993. "A Simple Model for Predicting the Effect of Electrolytes on the Vapor-Liquid Equilibrium Data of Solvent Mixtures." Separation Science and Technology 28 (5):1203-1210. doi: 10.1080/01496399308018030.

Latta, T. M., A. A. Palejwala, S. K. Tipson, and N. P. Haigh. 2016. "Design Considerations for Mitigating the Impact of Contaminants in Rich MEG on Monoethylene Glycol Recovery Unit MRU Performance." 2016/3/22/.

Latta, Thomas Michael, Marion Elisabeth Seiersten, and Scott A. Bufton. 2013. "Flow Assurance Impacts on Lean/Rich MEG Circuit Chemistry and MEG Regenerator/Reclaimer Design." 2013/5/6/.

Lu, Haiping, Amy T. Kan, and Mason B. Tomson. 2010. "Effects of Monoethylene Glycol on Carbonate Equilibrium and Calcite Solubility in Gas/Monoethylene Glycol/NaCl/Water Mixed Systems." doi: 10.2118/121562-PA.

McCabe, Warren L. 1993. Unit operations of chemical engineering / Warren L. McCabe, Julian C. Smith, Peter Harriott. Edited by Julian C. Smith and Peter Harriott. 5th ed.. ed. New York: New York : McGraw-Hill.

Meranda, David, and William F. Furter. 1977. "Elevation of the boiling point of water by salts at saturation: data and correlation." Journal of Chemical \& Engineering Data 22 (3):315-317. doi: 10.1021/je60074a023.

Molokanov, Yu, T. Korablina, N. Mazurina, and G. Nikiforov. 1971. "An approximate method of calculating the basic parameters of a multicomponent fractionation." Chemistry and Technology of Fuels and Oils 7 (2):129-133. doi: 10.1007/BF00718702.

Montazaud, Thomas. 2011. "Precipitation of carbonates in the pretreatment process for regeneration of ethylene glycol."Master Thesis, Chemical Engineering and Biotechnology, Norwegian University of Science and Technology.

Psarrou, Maria N., Leif O. Jøsang, Kristian Sandengen, and Terje $\emptyset$ stvold. 2011. "Carbon Dioxide Solubility and Monoethylene Glycol (MEG) Degradation at MEG Reclaiming/Regeneration Conditions." Journal of Chemical \& Engineering Data 56 (12):4720-4724. doi: 10.1021/je200709h.

Rossiter Jr, Walter J., McClure Godette, Paul W. Brown, and Kevin G. Galuk. 1985. "An investigation of the degradation of aqueous ethylene glycol and propylene glycol solutions using ion chromatography." Solar Energy Materials 11 (56):455-467. doi: http://dx.doi.org/10.1016/0165-1633(85)90016-4.

Smith, J. S., and J. D. A. Miller. 1975. "Nature of Sulphides and their Corrosive Effect on Ferrous Metals: A Review." British Corrosion Journal 10 (3):136-143. doi: 10.1179/000705975798320701.

Son, Kerry van, and Charlie Wallace. 2000. "Reclamation/Regeneration of Glycols Used for Hydrate Inhibition." Deep Offshore Technology Conference, New Orleans, LA.

Trimble, H. M., and Walter Potts. 1935. "Glycol-Water Mixtures Vapor Pressure-Boiling Point-Composition Relations." Industrial \& Engineering Chemistry 27 (1):66-68. doi: 10.1021/ie50301a015.

Wang, Gq, Xg Yuan, and Kt Yu. 2005. Review of mass-transfer correlations for packed columns. In Ind. Eng. Chem. Res.

Wilke, C. R., and Pin Chang. 1955. "Correlation of diffusion coefficients in dilute solutions." AIChE Journal 1 (2):264-270. doi: 10.1002/aic.690010222. 